COX, TERESA B., Ed.D. Fall Recovery Intervention and its Effect on Fear of Falling in Older Adults. (2014)

Directed by Dr. Kathleen Williams. 107 pp.

Fear of falling leads to activity restriction in the older adult population. Activity restriction leads to muscle deconditioning and a greater propensity to suffer a fall. Fear of falling may occur in older adults, regardless of their history of falls. The purpose of this study was to measure and compare the effects of a fall education program and a floor-rise training intervention on fear of falling scores, using the Survey of Fear of Falling in the Elderly fear of falling tool (SAFFE, Lachman, et al., 1998).

Lachman et al. (1998) developed the Survey of Activities and Fear of Falling in the Elderly (SAFFE) to ascertain the level of FOF associated with activities of daily living (ADLs) and/or instrumental activities of daily living (IADLs). ADLs include such tasks as feeding, toileting, selecting proper attire, grooming, maintaining continence, bathing, walking and transferring (CDC, 2013). IADLs include managing finances, handling transportation (driving or navigating public transit), shopping, preparing meals, using the telephone or some other communication device, managing medications, and housework (CDC, 2013). The SAFFE targets items consistent with previous research findings and FOF in the older adult population. The SAFFE survey tool assesses 11 activities associated with daily life maintenance, including going to the store, preparing meals, taking a tub bath, visiting friends or relatives, reaching overhead and to the floor, going out in slippery conditions, as well as getting out of bed, going to crowded places, exercising daily, and walking outdoors. It is a reliable and valid tool; its psychometric 
properties correlate with the Tinetti Falls Efficacy Scale (Tinetti, Richmond \& Powell, 1990).

Sixty-three older adults from two continuing-care retirement communities in Greensboro, ages 73-102, participated in a study in which a baseline fear of falling score was established. Educational material from the National Institutes of Health (CDC, 2013) was then given to all participants. Participants were subdivided, with 30 participants in an education-only group and 33 participants in the education and fallrecovery floor rise training group. In addition to the baseline survey, a second SAFFE was administered to all participants after the education intervention and lastly to both groups after the experimental group had received floor-rise training.

Using existing skills, the floor-rise training group performed three rises from a simulated fallen position. Whether attempting floor rise from either supine or prone position, each participant was able to rise from the floor under most conditions, using existing surroundings as aids if necessary (furniture, pillows, etc.). Floor-rise training methods were specialized for each individual, based upon hip and/or knee replacements, shoulder ailments, and any other preexisting condition that could make rising from the floor a challenge. Visual recordings of two floor-rise participants are included in this dissertation. It was hypothesized that both groups would decrease their fear of falling as a result of exposure to educational materials and floor-rise training. Intervention participants were hypothesized to experience additional decreases in fear. Results from this study examining data using a RM ANOVA were not significant, however. Increased 
confidence was evident in the qualitative aspects of the final interview, although not significant with the SAFFE survey tool. 


\title{
FALL RECOVERY INTERVENTION AND ITS EFFECT ON FEAR OF FALLING \\ IN OLDER ADULTS
}

\author{
by
}

Teresa B. Cox

\author{
A Dissertation Submitted to \\ the Faculty of The Graduate School at \\ The University of North Carolina at Greensboro \\ in Partial Fulfillment \\ of the Requirements for the Degree \\ Doctor of Education
}

\author{
Greensboro \\ 2014
}

Approved by

Committee Chair 
To all of those people in my life who kept hoping I could finish before I became eligible for social security. 


\section{APPROVAL PAGE}

This dissertation written by TERESA B. COX has been approved by the following committee of The Faculty of The Graduate School at The University of North Carolina at Greensboro.

Committee Chair

Committee Members

$\overline{\text { Date of Acceptance by Committee }}$

Date of Final Oral Examination 


\section{ACKNOWLEDGEMENTS}

Since 1996, I have lived a dream. I began a new life path seeking an undergraduate degree at the age of 42 here at UNCG. This has been an amazing journey. I am so very grateful for the many folks who have touched my life, paved my way, and helped turn my head in the right direction to stay focused.

First and without doubt, my committee chair, Dr. Kathleen Williams, deserves the biggest and most heartfelt "thank you” for staying with me throughout this rather lengthy journey. She has shown me both compassion and drive as she has done so much for me, when she had so much to do for so many others. I am truly humbled with appreciation.

Additionally, my committee has supported me as enthusiastically as I could have ever hoped for. Merely saying that I appreciate them, seems inadequate to the reality of how I feel. Dr. Paul Davis, Dr. William Karper, and Dr. Janice Wassel are truly the best team one could hope for.

I would like to honor Dr. Linda Buettner, whose gleaming smile and resilient spirit floated away and is now high above us during my work on this dissertation. She is permanently a bright and forever shining star, looking down with her waif-like grin, so proud and still saying "I know you can do this" from the heavens.

I would like to thank my husband for staying hopeful and present during these long years of my swinging from wide perigee to apogee in this degree. It now seems unfathomable that it took me so long to swing finally toward the last stages of this degree program. 
Particularly I would like to thank the participants in my study, who worked graciously rising from the floor, over and over again, so pleased with themselves for having gotten up from a position from which they might not have believed they could have risen. Their time investment was huge, and yet they seemed so willing to stay for long training sessions and to have a good time doing so.

Lastly, though in no way least, I thank my sister Shari for her tireless hours performing the final surveys on the participants. Data collection does not sound like a fun way to spend the spring and summer days, but she never complained.

Of course, thank you seems small but so important to the two people who read and re-read the results of this study, Amanda Byrd but particularly Dr. Kathleen Williams, whose editing help and advice truly saved me from myself. 
TABLE OF CONTENTS

Page

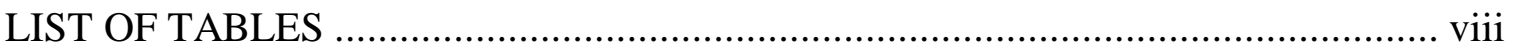

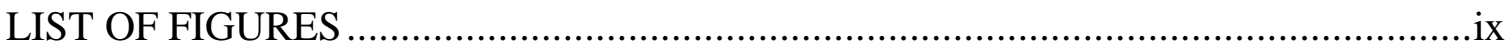

\section{CHAPTER}

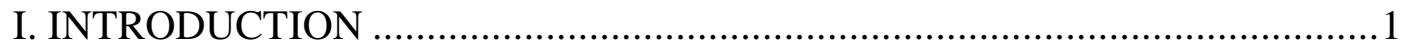

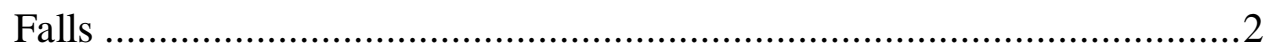

Fear of Falling ..................................................................................

Physical Changes Due to FOF ……………………….........................5

Exercise Intervention Targeting FOF-Related Activity Restriction ..........................................................................

Statement of the Purpose .......................................................................

Limitations ......................................................................................

II. REVIEW OF THE LITERATURE .........................................................14

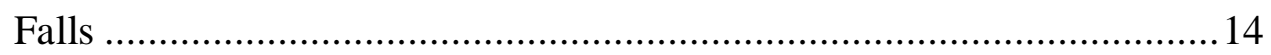

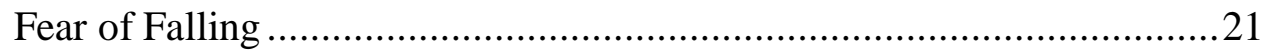

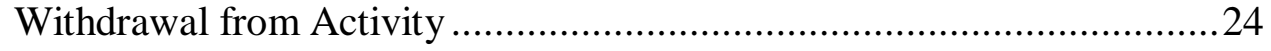

Interventions that Target Falls and FOF ..............................................28

Floor-Rise or Fall-Recovery Training ....................................................30

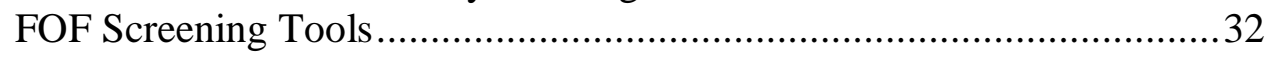

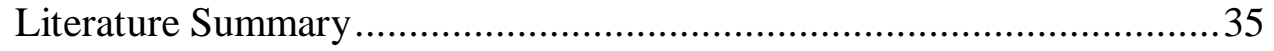

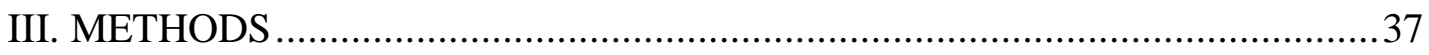

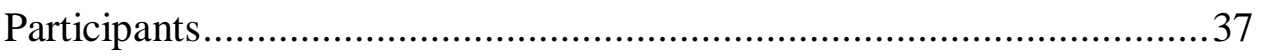

Fear of Falling Instrumentation ..............................................................38

Sample Power.....................................................................................42

Hawthorne-Effect in Practice-Based Research .......................................42

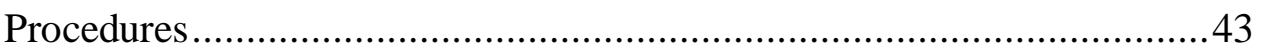

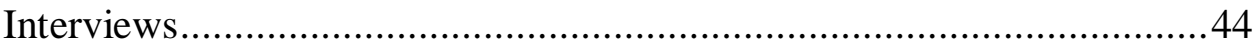

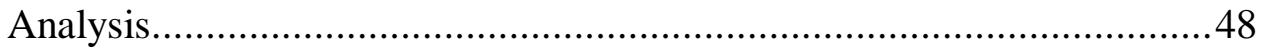

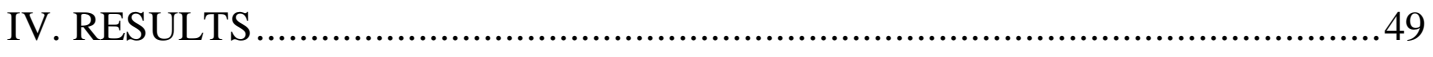

Descriptive Data .................................................................................49

Summary of Results............................................................................54 


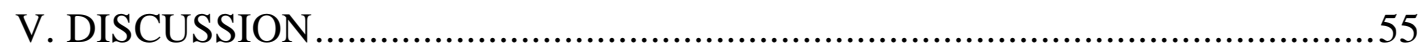

Alternative Sources or Causes of Activity Restriction.........................56

Research Implications and Future Directions....................................59

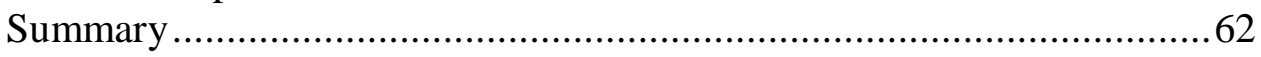

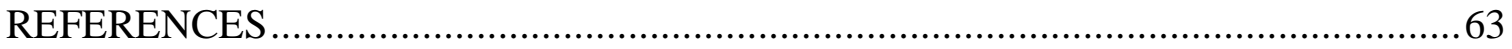

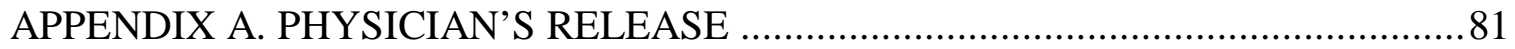

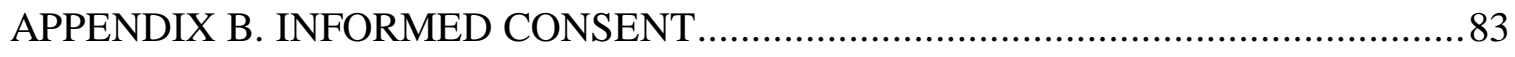

APPENDIX C. RECRUITMENT IN NEWSLETTERS .......................................... 86

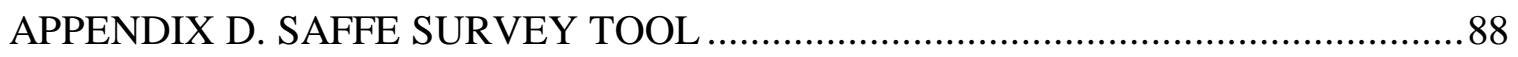

APPENDIX E. AUTHORIZATION FOR PHOTOS AND FILMING ........................94 


\section{LIST OF TABLES}

Page

Table 1. Descriptions, FOF Scores per Activity for Control and

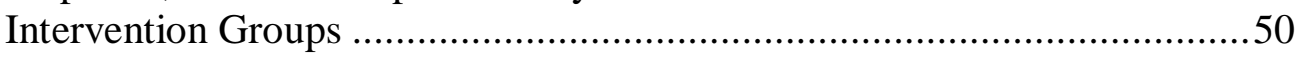




\section{LIST OF FIGURES}

Page

Figure 1. Mean Values for 3 SAFFE FOF Results................................................52

Figure 2. Mean Values for High Fear Activity - Slippery Surfaces (n=63) ..................54 


\section{CHAPTER I}

\section{INTRODUCTION}

Falls are a common and often devastating problem for all people but can be both physically and mentally crippling to the older adult. Older adults are more likely than younger people to experience an unpredictable or unexpected fall (Hausdorff, Rios, \& Edelber, 2001). Falls are among the most common and serious of health concerns facing older persons (Howland, Person, \& Lachman, 2001). Because fall rates in the general older population are estimated at 1.2 falls per person-year, finding an effective intervention is an urgent global challenge (Ganz, Bao, Shekelle Laurence, \& Rubenstein, 2007).

Whether actually having experienced a fall or not, some older adults develop fear of falling and often disengage from physical, social, and/or leisure activities. Such disengagement from activities, typically referred to as fear of falling (FOF), has the potential to lead to degradation of muscle tone and core balance, often leading to a higher propensity to fall. FOF is one of the extremely disabling components of aging, as it actually prevents the optimal level of functioning for the older adult (Tennstedt, Howland, Lachman, Peterson, Kasten, \& Jette, 1998). This fear can and does lead to a reduced quality of life for the older adult. The goal of this research project was to test and compare fall education and fall recovery (floor-rise training) in an older adult population and to intercept or reverse this FOF trajectory. 
Falls

Falls are most often defined as "any event in which a person inadvertently or unintentionally comes to rest on the ground or another lower level such as a chair, toilet or bed” (Tideiksaar, 2002, p. 15). While falls can cause serious problems for any person of any age, the rapid growth in population of adults over 65 years old in the United States makes this a potentially devastating problem because this age group tends to be feebler and suffer more long-term devastating effects resulting from falls. Falls are a risk factor for disability and frailty and intensify the disablement process in older adults (Verbrugge \& Jette, 1994). The proportional size of this population is projected to increase from 12.4 percent in 2000 to 19.6 percent by 2030 ; the number of persons over 80 years is expected to increase from 9.3 million in 2000 to 19.5 million in 2030 (U.S. Census Bureau, 2005).

Existing literature reveals a robust link between falls in the elderly and disabling injury or death (National Safety Council, 2008). The severity of fall-related medical complications increases with age, as does mortality rate, regardless of gender, ethnicity and /or race (O’Loughlin, Robitaille, Boivin, \& Suissa, 1993). Falls account for the most common reason for hospitalization in the population over 65 years old (Diener \& Mitchell, 2005). For adults over age 75, falls constitute 70 percent of all accidental deaths. The most frequent fall-related injuries include hip, wrist and head fractures as well as damage to internal organs (Stevens, 2006). Additionally, approximately 25 percent of older adults living in an independent community require nursing home care following a hip fracture (Magaziner et al., 2000). 
Although not exclusive to the older adult, extrinsic factors may precipitate falls. These factors include environmental hazards associated with steps or stairs (e.g., lack of hand-railing), poor or inadequate lighting, or tripping hazards such as throw rugs or furniture (Gill, Williams, \& Tinetti, 2000). Lack of familiarity with surroundings (e.g., poor sidewalk, paving conditions, pets or pet-related items) might also increase the likelihood of a fall (Norton, Campbell, Lee-Joe, Robinson, \& Butler, 1997; Stevens, 2006). These conditions and circumstances might become more severe as older adults become feebler and experience muscle strength loss as well as poor or compromised reaction time (Norton et. al, 1997; Stevens, 2006).

Conversely, intrinsic factors contributing to falls in older adults include physiological changes associated with aging (gait changes, imbalances), arthritis, deconditioning due to immobility, orthostatic hypotension, polypharmacy, delirium, anemia, diabetes mellitus, Parkinson's disease, depression, vision defects, cognitive impairment, syncope, complex partial seizures in the parietal or occipital lobes, and vitamin D deficiency (Morley, 2007). Sensory problems, such as neuropathy, may reduce neurological feedback, thus desensitizing extremities to changes in surfaces (Stevens, 2006).

Fear of Falling

Older adults may develop the fear of falling (FOF) in the absence of an actual fall. In the early phase of research, FOF was believed to be a consequence of falling or the psychological trauma from a fall (Tinetti, Richman, \& Powell, 1990). Later research revealed that FOF often led to reduced activity and accompanying loss in physical 
capacities. It was reported FOF may cause older persons to lose confidence in their ability to function safely (Gill, Williams, Williams, \& Hale, 1998). While previous research sought to focus on environmental changes that could be modified to reduce FOF, Velozo and Peterson (2001) developed a program for older adults to instill confidence, improve balance and encourage engagement in an exercise program. While successful in lowering FOF in senior housing establishments, this program was not applicable in community settings. Newer research reveals that FOF is more complex than just an apprehension about falling (Howland, Peterson, \& Lachman, 2001; Letgers, 2002). In recent years, FOF has been identified as a substantial health issue for older adults both physically as well as psychologically (Dias et al., 2011; Howland, Peterson, \& Lachman, 2001; Letgers, 2002).

The significant behavioral and functional curtailment of leisure-time physical activity by older adults experiencing FOF occurs in approximately one half of all older adults who have experienced a fall within one year (Kressig et al., 2002). While some reduction in activity might be due to a fall-related injury and ensuing recovery period, FOF has been noted as an exclusive factor in many activity limitations as reported by older adults (Kressig et al., 2002). Even people who have not experienced a fall report FOF as an important factor in disengagement from leisure-time social activities. Fear of falling may then become a risk factor for future falls, particularly if this fear leads to a serious curtailment in physical activity (Kressig et al., 2002). Finding out why not all older adults who fall develop FOF has become a major focus in recent research, 
uncovering why older adults who have never fallen develop irrational FOF is equally important (Huang, 2005).

FOF is a dynamic and cumulative condition that becomes more pronounced in those who are suffering from it. This worsening trajectory causes the older adult to "hyper-react" to events or situations, perhaps even exacerbating a fall (Huang, 2005). As this negative spiral continues and anxiety seems to escalate, engagement in leisure or social activities often decreases (Huang, 2005). Physical deconditioning, muscular and skeletal weakness tend to develop under these circumstances, and all then may lead to further self-imposed restrictions on activity, which increases risk for falls (Kressig et al., 2002).

Negative characteristics have been observed in older adults who exhibit FOF. Outward physiological and psychological symptoms of FOF can mimic depression, fallrelated decline in self-efficacy or locus of control, as well as reduced functional capacity for daily activities and participation in leisure activities. FOF can lead to frailty and is therefore almost exclusively responsible for a decreased health self-perception in older adults, particularly in those that reduce or restrict activities solely due to avoid or prevent future falls (Dias et al., 2011). Physical Changes Due to FOF

A marked withdrawal from social activities is a social consequence of FOF that has been linked with psychological symptoms resembling depression in the older adult population (Huang, 2005). Such social withdrawal has a negative impact on the quality of life of the older adult (Huang, 2005; Scheffer, Schuurmans, van Dijk, van der Hooft, \& 
dee Rooij, 2008). Lachman et al. (1998) noted that increased FOF is associated with decreases in quality of life, most of which is due to declines in social interactions. Studies designed to differentiate and identify physical factors associated with FOF and activity restriction show marked frailty, reduced functional capacity for activity, as well as a higher propensity to future falls (Dias et al., 2011).

Additionally, physical decline has been noted in hospitalized older adults who report FOF during either a short- or long term hospitalization (Boltz, M., Resnick, B., Capezuti, E., \& Shuluk, J., 2013). Those hospitalized older adults report that FOF and acute activity restriction (during the hospital stay) decreased the self-direction needed to engage in activity. This lack of self-direction may hinder recovery, particularly when the older adult has been hospitalized due to a hip or knee replacement or procedure. Older adults who were depressed during initial hospital entry were most likely to develop activity restriction as a result of FOF during the hospital stay. Physical and mental disabilities such as these are termed "hospital-acquired disability" and may impact the physical and cognitive functioning of the older adult returning to independent living quarters outside the hospital surrounding. Boltz, et al. (2013) noted that it is critical to the continued health and well-being of hospitalized older adults who report FOF for staff and support teams to encourage self-direction. This approach may assist in keeping the older adult active during the hospital stay to assure speedy and complete orthopedic recovery under such circumstances. Loss of focus on the self-direction needed to comply with physical therapy sessions may result in the loss of physical capacity for activity and hamper recovery (Boltz et al., 2013). 
Muscle deconditioning due to FOF-related activity restriction has been linked with changes in gait velocity and balance in the older adult population (Barker, Nitz, Low Choy, \& Haines, 2009; Reelic, van Iersel, Kessels, \& olde Rikkert, 2009). Such gait variances may lead to continued instability in walking for the older adult, resulting in even greater FOF. While the prevention of falls in older adults is of primary importance, methods that encourage reengagement in social and leisure physical activities, while reducing FOF, are equally important. Decreases in activity levels can lead to physical deficits that mimic the aging process, e.g., muscle weakness, strength loss and osteoporosis (Stevens, 2006). Physical inactivity is associated with higher mortality rates as compared to the rates for moderately active older adults (Metter, Talbot, Schrager, \& Conwit, 2002). FOF sufferers who disengage from leisurely physical and social leisure activities experience greater functional decline in activities of daily living (ADLs) and are then less likely to re-engage in such activities. Recurrent falls and serious injury become more likely with the accumulation of these additional significant fall risk factors (Grisso et al., 1991; Rubenstein, 2006; Tinetti, 2003; Tinetti et al., 1988; Vellas et al., 1987). FOF-related activity withdrawal then becomes a risk factor for falls in the older adult (Grisso et al., 1991; Rubenstein, 2006; Tinetti, 2003; Tinetti et al., 1988; Vellas et al., 1997).

\section{Exercise Intervention Targeting FOF-Related Activity Restriction}

Evidence in literature exists for a positive relationship between physical activity intervention and fall risk and actual fall reduction in the older adult population (Chang et al., 2004). In a meta-analytic review of 40 exercise trial interventions, Chang et al., 
(2004) found a statistically significant beneficial effect on both risk of falling and monthly rate of falling. Most of the studies reviewed had multifactorial exercise or intervention modalities. None of the studies were able to measure, and thereby demonstrate, the relative effectiveness of the specific intervention components. This review noted that researchers measuring FOF as well as balance and muscle strength often reported physical improvements but found that FOF was predominately unaffected. Initiating an exercise program in an older adult suffering from FOF is often challenging. The person may be so fearful of experiencing a fall that he/she feels safer staying disengaged. Finding ways to help the older adult reduce or eliminate the fear long enough to start such an exercise program might actually give the older adult a greater sense of confidence. Developing a specific exercise or intervention program that resulted in more efficacy and confidence was critical to the older adult suffering from FOF (Chang et al., 2004).

In a separate meta-analytical review looking just at studies that targeted FOF, Zijlstra, van Haastregt, van Rossum, van Eijk, Yardley, \& Kempen ( 2007) analyzed 19 randomized, controlled trials and evaluated effectiveness of the FOF interventions. These studies targeted community-living older people. Fall prevention was effective in studies with durations ranging from a single one-hour visit to weekly exercise/treatment sessions for one year. As for FOF, Zijlstra et al. (2007) found that home-based interventions were more effective than those delivered in a community-group setting. This review speculated that the home-based interventions were less threatening to the older adults, and they seemingly performed better through the tasks with a more personal 
approach to the training. All of the interventions reviewed were multimodal; except for two, which were Tai Chi. Chang et al. (2004), as well as Zijlstra et al. (2007) noted that fall-recovery training was absent in all of the observable interventions. Teaching floorrise training was suggested as a training mode to introduce an exercise intervention for atrisk older adults (Hofmyer, Alexander, Nyquist, Medell, \& Koreishi, 2002). Older adults taught such fall-recovery methods showed improvement in rising from a floor position, and the training was recommended as an exercise modality (Hofmeyer et al., 2002). Statement of the Purpose

The purpose of this study was to measure what effects both fall education and fall-recovery training had on FOF scores as measured by the SAFFE using a repeated measures ANOVA.

There were two hypotheses:

1. Both groups would have lower FOF scores after the fall education training over baseline scoring use SAFFE.

2. The experimental group would have lower FOF scores (overall) after fallrecovery training over both baseline scoring and post-education scoring using SAFFE.

Participants were randomly divided into two groups and assigned to either the control group or the experimental group. Baseline FOF scores were established using the SAFFE (Lachman et al., 1998) survey tool. Both groups received education sessions using the fall-proofing and education material provided by the NIH (2013). At that time, the second SAFFE was administered to both groups. The control group received no 
additional treatment, while the experimental group received fall recovery (floor-rise) training protocol either in small group sessions or individually. Final FOF scores were assessed by administration of a third SAFFE for both groups. To reduce the possibility of bias, this final SAFFE was administered by a party not affiliated with participants previously during any part of this research project.

More specifically, the intervention program(s) proposed for this study consisted of an educational program targeting falls as well as fall recovery (floor-rise) training sessions, a procedure that teaches the older adult to rise from the floor by introducing or honing existing skills necessary to complete the maneuver. Fall recovery, or teaching older adults how to get up from a fall, was cited as consideration for future studies in exercise intervention, particularly when focusing on FOF (Chang et al. 2004; Gates et al., 2008; Zijlstra et al. 2007).

There is clear value added to health and quality of life for an older adult who reverses symptoms of FOF, particularly activity restriction. There could be a significant impact on health care costs in our society. Although manifestation of fear of falling is most common after a fall or multiple falls, it also occurs without a fall or fall history. Due to the acute and devastating psychological outcome of falls for an older adult, fear of falling often leads to self-imposed activity restriction, which leads to a loss of functional mobility and independence (Tinetti, et al., 1990). Reducing FOF may provide a way for older adults to avoid or reverse this activity restriction and the ensuing downward spiral. Activity restriction associated by FOF has been defined in current literature as a socialdemographic, clinical, functional and psychological phenomenon which can lead to a 
decline in self-efficacy, frailty, reduced functional capacity, depressive symptoms, and a reduced health self-perception in the older adult (Dias et al., 2011). Older adults who have FOF and ensuing activity restriction may exhibit symptoms of exhaustion and depression, which are the negative effects on functional capacity and psychological wellbeing (Dias et al., 2011).

The uniqueness of this intervention is of major importance to the aging population who experience FOF. An extensive research and literature review failed to yield other interventions of similar design. Floor-rise training, while previously mentioned, has not been attempted in previous research studies. The results from this study might have major implications for future studies that target FOF.

Interventions that successfully reduce FOF have been implicated as being likely to reduce the incidence of falls in the older adult population, specifically by reintroducing the older adult back into activity. In addition, current researchers continue to report links between measured FOF and a history of falls, which may come after the onset of FOF (Zarkou, Aggelousis, Michalopoulou, \& Tokmakidis, 2011). Fall recovery or floor-rise training may provide a platform for future interventions that target FOF and may thereby help to reinforce or reinstate the confidence needed to stay engaged in previously enjoyed activities, preserving the older adult's quality of life Zarkou et al., 2011).

\section{Limitations}

1. Older adults experience frailty at varied levels, depending on the range of life and recent experiences, health, and other variables. Defining expectations for fall- 
recovery sessions involved specific physician’s guidelines for specific individuals in this study. The results of FOF studies using SAFFE have never been compared with using just fall recovery (floor-rise) tactics as an intervention. Findings may not be generalizable to other SAFFE studies.

2. Although older adults may have been able to get up from a reclined position, few had specific training or experience with rising from the floor or from a raised padded surface. This entire maneuver proved novel to most participants in the study. Existing aids or devices found within the apartments of participants in the study were incorporated for use in rising from the floor as needed.

3. Since rising from a "fallen" position was new for most of the participants, the events surrounding the intervention had the potential to produce anxiety for the older adults. To assist in anxiety reduction, members of the nursing and/or maintenance staff were advised of these training sessions. A therapy mat table was utilized to serve as a soft "bumper” surface.

4. Conducting an educational and instructional session on the hazards of falling could have caused the older adults to become hypersensitive on the day of the intervention. Doing floor-rise fall recovery tactics in their apartments when possible was done to make them feel more comfortable.

5. As Shubert, Altpeter and Busby-Whitehead (2011) noted, the mechanism for turning a small intervention research design into a community-wide intervention in a fall study can prove challenging. Assuring that the targeted population older adults -attend such an intervention was a core element in this research as 
was making sure that the end product was appealing to deliver the program to a large audience safely and effectively. Partnerships between community and health care providers might be the key component in successfully making this fall recovery program generalizable (Shubert et al., 2011).

6. An assessment of the Hawthorne Effect suggests that a practical, repeated datacollection methodology such as the protocol for this research might have yielded false-positive results in the final data collection of the SAFFE. Subjects who received extra attention might have been prone to "help" the researcher find the results sought in the study. Data collection for the final SAFFE was performed by a trained interviewer who was not biased toward the research or the outcome (Fernald, Coombs, DeAlleaume, \& Parnes, 2012). 


\section{CHAPTER II}

\section{REVIEW OF THE LITERATURE}

This chapter will summarize the following topics: falls, fear of falling, activity restriction and targeted exercise interventions, including floor-rise or fall-recovery training specific to seniors. Getting older adults more active as a fall prevention tool is an ultimate goal of this study, and reducing FOF through fall-recovery intervention training is a short-term methodology to reach that goal. Evidence will be presented by examining various exercise intervention strategies that target strength and balance for the older adult, and strategies specific to fall-recovery training. Additionally, an evidence-based rationale for multidimensional fear of falling (FOF) screening for adults older than 65 years of age will be explored.

Falls

Falls and unstable balance rank high among serious clinical problems faced by older adults (Rubenstein, 2006). They are a singular cause of sustained increases in the rates of mortality and morbidity as well as major contributors to immobility and premature nursing home placement. Rubenstein and Josephson (2002) projected that 30 - 50 percent of individuals 60 years and older will fall repeatedly. Unforeseen injuries due to falls are the fifth leading cause of death in older adults after cardiovascular disease, cancer, stroke and pulmonary disorders. In the United States, about three-fourths 
of deaths due to falls occur in the 13 percent of the population around or greater than age 65, indicative of a propensity almost entirely exclusive to the older adult (Rubenstein, 2006). Falls are the leading cause of unintentional injuries in the United States across all age groups (CDC, 2006). Injury rates are highest in the older (over 65) and younger (014) age groups (CDC, 2006; Sterling, O'Connor, \& Bonadies, 2001). Falls can and do have crippling long-term effects for individuals and their families. About 5 percent of falls in older adults cause a fracture or necessitate hospitalization (Rubenstein, 2006). Falls are among the most common and serious of health concerns facing older persons (Howland, Person, \& Lachman, 2001).

Results from many population-based epidemiological studies indicate fall rate for the older adult population varies considerably (Rubenstein, 2006). These differences are often attributed to home setting, safety concerns and as self-report of falls by older adults living in independent-living communities. Falls that lead to hospitalization often are the only ones reported, thus leading statisticians and researchers to assume some ambiguity in the actual fall numbers for all older adults (Tideiksaar, 2002). The healthier, relatively active community-living older adults around the age of 65 or greater experience the lowest number of falls per year (0.3 - 1.6 falls per person annually) (Rubenstein, 2006). The rate of falls and their associated complications rise steadily with age and are about twice the rate for persons older than age 75 years as the rate for those older than 65 . People living in long-term care facilities have much higher fall rates that often result in more serious complications, with approximately 10-25 percent of those falls resulting in fracture or laceration (0.6-3.6 per bed annually, mean 1.7). Falls among those in 
institutionalized care facilities also tend to result in more serious complications, with 1025 percent of such falls resulting in fracture or skin tears (Rubenstein, 2006).

In 2008, the CDC analyzed data from the Behavioral Risk Factor Surveillance System (BRFSS). Interviews with 92,808 adults over 65 years of age were included. The survey results indicated that 15.9 percent of the adults had experienced more than one fall in the previous three months; 23.1 percent reported falling three or more times in the same time period (CDC, 2008). A fall-related injury was reported in 31.3 percent of the fallers, regardless of age group (CDC, 2008).

A history of previous falls places individuals at increased risk for repeated falls. Chang et al. (2004) reported that older adults may not remember minor falls or are unwilling to report falls due to humiliation or fear of losing self-sufficiency in their living situations. Such falls may not be witnessed by other family members, caregivers, etc., and therefore actual fall figures may be underreported (Cummings, Rubin, \& Black, 1990; Faulkner et al., 2009; Tinetti 2003).

Speechley and Tinetti (1991) developed a method of categorizing various types of falls in the older adult population as well as the types of fallers. They believed that such information could help clinicians devise preventative interventions to curb fall-rate increases as noted in older adults. Analyzing data from 336 independent-living older adults, they noted that yearly fall rates were highest in the frail group (52 percent) and lowest in the most vigorous group (17 percent). The categorization of groups as frail or vigorous was based upon physical, psychological, and demographic characteristics. Serious injury occurred in 22 percent of the vigorous adult group and only six percent of 
the frail group. Circumstances leading to injury in the vigorously active group included displacement activities, environmental hazards, and stair climbing. Activity-related instances of falls or causes of falls appeared with greater frequency in this active group than within the frail group. More vigorously active older adults places themselves at higher risk by engaging in higher-risk physical activities, often exhibiting little or no fallfear. Recommendations from the Speechley and Tinetti study (1991) were that fall and injury prevention as well as fall-specific exercise interventions should target all adults, not just those who are frail.

Falls are a common threat to older adults and can jeopardize their independence and daily functioning, a fact indicating that falls and fall-related injuries pose a serious public health problem. Of particular importance is the fact that the population aged 65 and over is the fastest growing sector of the United States, and it is expected to double by the year 2030 (He, Sengupta, Velkoff, \& DeBarros, 2005).

In 2005, 15,800 people 65 and older died from injuries related to falls; about 1.8 million people 65 and older were treated in emergency departments for nonfatal injuries from falls, and more than 433,000 of these patients were hospitalized (CDC, 2005). Gender differences exist for falls in the older age groups, with females experiencing a greater number of falls. Non-fatal fall injuries for females are 49 percent higher than for males, although men are more likely to die from a fall. After adjusting for age, the fall fatality rate in 2004 was 49 percent higher for men than for women in the United States (CDC 2005). Rates of fall-related fractures among older adults are more than twice as high for women as for men (Stevens et al. 2005). In 2003, about 72 percent of older 
adults admitted to the hospital for hip fractures were women (CDC, 2005). In 2001, the rates of fall injuries for adults 85 and older were four to five times that of adults 65 to 74 (Stevens et al., 2005) . Nearly 85 percent of deaths from falls in 2004 were among people 75 and older (CDC, 2005). People 75 and older who fall are four to five times more likely to be admitted to a long-term care facility for a year or longer (Donald et al. 1999).

Between 2001 and 2005 in the United States, death rates after falls, increased significantly among both genders but continued to be higher in males (CDC, 2008). This trend was true for all ethnicities, with Caucasians in the U.S. experiencing the highest fatal fall rates. The rise in fatal fall rate during this period has been accounted for by two components: increased longevity means that the number of older adults living with chronic disease has increased, and secondly, such chronic conditions, when coupled with advanced age, lessens the likelihood of surviving an injurious fall (CDC, 2008). Survival after an injury-related fall becomes more challenging with advancing age (Stevens, 2006).

Falls in older adults often follow a vicious trajectory: (1) fall-related hospitalizations in the older adult include extended recovery times; (2) longer hospitalization periods result in muscle de-conditioning and probable anxiousness; (3) physical deconditioning, as well as "fall-anxiety" quickly lead to declines in (or withdrawal from) normal activity level (Delbare, Crombez, Vanderstraeten, Willems, Cambier, 2004; Rubenstein, 2006; Tinetti, 2003; Tinetti et al., 1988; Vellas et al., 1997). This cycle culminates in a fear of falling (FOF), which carries the potential of further 
degradation of muscle tone and core balance, often leading to a higher propensity for falls (Lach, 2003). The consequences of a fall can include impaired gait and balance, which can be responsible for a continued loss of confidence and further restriction of activity level(s) (Delbare, et al., 2004; Rubenstein, 2006; Tinetti, 2003; Tinetti et al., 1988; Vellas et al., 1987). According to The National Health Interview Survey, falls account for 18 percent of the restricted activity days among older adults, and are the largest single cause of restricted activity (Kosorok, Omenn, Diehr, Koepsell, \& Patrick, 1992; Rubenstein, 2006). It is understandable that FOF is a real health problem in the United States, as falls can devastate the life of an older adult (Lach, 2003).

Stevens et al. (2006) provided national estimates of incidence and direct medical costs associated with fall-related injuries among older adults in the United States. The data used were from the 2000 National Vital Statistics Systems, 2001 NEISS-AIP, 2000 Health Care Utilization Program National Inpatient Sample, and the 1999 Medical Expenditure Panel Survey (Stevens et al., 2006). National fall-related injury costs of over 31 billion dollars reported each year have been cited in government CDC reports, and these projected costs are estimated to rise exponentially until the year 2020 (CDC, 2005; Stevens et al., 2006). These fall-related injury costs do not take into account the longterm consequences of fall related injuries. These consequences include loss of independence, loss of confidence, susceptibility to recurrent falls, and increased mortality (Stevens et al., 2006). Among older adults who sustained a fall related injury, 38 percent required assistance for ADLs after the fall, and 58.5 percent of these elders are estimated 
to continue to require assistance for at least an additional six months (Stevens et al., 2006).

When looking specifically at the epidemiology of risk factors for falls in the older adult, more than 400 variables have been identified (Gillespie, Gillespie, Robertson, Lamb, Cumming, \& Rowe, 2003). Fall risk embodies a complex, multifactorial combination of both intrinsic and extrinsic determinants. Intrinsic risk factors for falls, which are those things that self-originate and increase the chances of a fall, correlate with an older adult's health, functional status and as physical characteristics (Gillespie et al., 2003). Age-related declines in physical functioning (e.g., balance, muscular and structural strength, mobility, gait changes, performance of activities of daily living, cognitive, auditory and visual functioning) and a variety of psychological factors - such as depression, anxiety and fear of falling - are some of the most frequently noted risk factors. Selforienting abilities like maintaining balance after a slip or avoiding a fall by way of a rapid step, etc., decline with aging. Other intrinsic factors in falls in the older adult are medical conditions such as peripheral neuropathy, previous stroke, bladder incontinence, Parkinson's disease or any disorders of the central nervous system, foot complications, and orthostatic hypotension (Gillespie et al., 2003; Rubenstein, 2006).

Extrinsic risk factors for falls - circumstances or objects relating to a person’s interaction with his/her environment - include poor lighting, loose carpets, slippery floors, inadequate safety railing in bathrooms and fixtures, and unsafe stairways (Rubenstein, 2006). Additionally, an elevation in fall-risk is associated with polypharmacy (typically referred to when the patient uses four or more prescription medications), use of walking 
aids or devices, and any activities associated with a higher fall risk - for example, icy sidewalks, slippery floors (Steinweg, 1997; Gillespie et al., 2003; Rubenstein, 2006). Fall risk is compounded by unsafe or hazardous extrinsic factors around the home (CDC, 2008; Samelson, Zhang, Kiel, Hannan, \& Felson, 2002). Many older adults have multiple identifiable risk factors for falls, a situation which makes the exact cause of any single fall difficult to identify (Gillespie et al., 2003; Rubenstein, 2006).

\section{Fear of Falling}

Fear of falling (FOF) is a "lasting concern about falling that leads an individual to avoid activities that he/she remains capable of performing” (Tinetti, 2003, p.42), and it is the most explored fall-related psychological construct. Early research in falls produced many theories about FOF. Researchers Marks \& Bebbington conceptualized in 1976 that FOF might be an unusual departure from agoraphobia, most often defined as an abnormal fear of open spaces or public places. Later, Bhala, O’Donnell, \& Thoppil (1982) described FOF as “ptophobia,” which means a phobic reaction to standing or walking. Murphey \& Isaacs (1982) subsequently classified FOF as “post fall syndrome.” Possessing some element of FOF can be safe and beneficial because it can instill increased caution during activity performance that promotes effective coping skills for falls prevention (Lachman et al., 1998). By possessing a healthy concern about avoiding risky situations, older adults can be more attuned to potential safety hazards and they can pay greater attention to navigating safely in their environment. In contrast, a more pronounced fear can translate into increased activity restriction (Li, Fisher, Harmer, McAuley, \& Wilson, 2003; Tinetti \& Powell, 1993), reduced social interaction (Arfken 
et al., 1994; Howland et al., 1993; Howland et al., 1998), decreased quality of life (Lachman et al., 1998; Li et al., 2003), poor subjective health rating (Howland et al., 1998), generalized anxiety (Lawrence et al., 1998), depression (Delbaere, Crombez, Vanderstraeten, Willems, \& Cambier, 2004), reduced physical capabilities - for example, reduced capacity to perform instrumental activities of daily living (IADL), poor balance, poor functional mobility (Howland et al., 1998; Li et al., 2003), and ultimately a sedentary lifestyle (Bruce, Devine, \& Prince, 2002). In its most oppressive form FOF is as an expression of anxiety, apprehension, and uncertainty, all of which can lead to a loss in confidence or self-efficacy, thereby putting an older adult at greater risk of a fall (Delbaere et al., 2004; Lachman et al., 1998; Murphy \& Isaacs, 1982). This more debilitating form of FOF becomes a risk factor for falls (Lachman et al., 1998; Tideiksaar, 1997). Even with skepticism about ability, many older adults do not consider themselves to be fearful of suffering a fall (Lachman, et al., 1998; Tideiksaar, 1997). Although these older adults might have felt threatened by the possibility of a fall or even have modified their behavior to avoid falling, their perceived FOF is still very low (Lachman, et al., 1998; Tideiksaar, 1997). Alternatively, some older adults may try to conceal their fear to avoid stigmatization or exaggerate it to gain sympathy. Subsequently recent attempts to measure FOF have focused on evaluating people's confidence at avoiding a fall as opposed to their fear, which has led to the operationalization of FOF as a falls-specific form of self-efficacy (Tinetti et al., 1990).

Early researchers attempted to measure FOF using a generic, single-item question with a dichotomous response in which survey participants were asked if they were afraid 
of falling (Arfken et al., 1994; Maki et al., 1991; Tinetti et al., 1990; Walker \& Howland, 1991). Such a screening method has proven adequate in research studies where participants are classified into "afraid of falling” and "not afraid of falling” groups (Arfken et al., 1994; Maki et al., 1991; Tinetti et al., 1990; Walker et al., 1991). This dualistic protocol allowed researchers to test the psychological outcomes of falls prevention and/or educational interventions using experimental and control groups (Arfken et al., 1994; Maki et al., 1991; Tinetti et al., 1990; Walker et al., 1991). In later studies, Tinetti and collaborators ascertained that assessing FOF using this protocol was not describing or addressingmthe full psychological impact of falls, which ultimately led to the development of FOF (Tinetti et al., 1990).

Tinetti et al. (1990) referred to previous research conducted on self-efficacy by Bandura (1982) that implies that transient conditions such as fear are insufficient predictors of static behaviors. Self-efficacy relates to an individual's belief or confidence in his or her own capacity to carry out a specific activity or task successfully (Bandura, 1986). Bandura (2004) theorized that an individual with low self-efficacy would experience poorer outcomes and would be more likely to give up when facing a challenging task, whereas an individual with high self-efficacy would persevere and successfully complete a task in the face of adversities. Tinetti et al. (1990) determined that a yes/no approach to self-efficacy was inadequate, spurring them to develop the Falls Efficacy Survey (FES), which was grounded in Bandura’s self-efficacy theory (Bandura, 1977, 1986; Tinetti et al., 1990). Tinetti and colleagues (1990) designated FOF as low 
fall-related self-efficacy for averting falls while engaging in common activities of daily living (ADLs), based upon the outcome measure of the FES.

Since falls and fall rates are predictors for future falls and are associated with other adverse health outcomes such as FOF, it is important to know the extent of falls among older adults (Letgers, 2002; Jorstad, Hauer, Becker, \& Lamb, 2005). Falls and FOF are interrelated problems because each is a risk factor for the other (Suzuki, Ohyama, Yamada, \& Kanamori, 2002). A large number of older adults who experience fall(s), whether or not an injury is sustained, develop FOF, which can lead to restricted activity, a decline in social interactions, depression and an increased risk of falling (Letgers, 2002; Jorstad et al., 2005).

\section{Withdrawal from Activity}

As previously determined, FOF has been recognized as a serious and common problem in older persons that may not necessarily be preceded by an actual fall. In an attempt to avoid fall-related morbidity and social embarrassment, many fearful older persons restrict activities (Deshpande, Metter, Lauretani, Bandinelli, Guralnik, \& Ferrucci, 2008). For the older adult, the psychological impact related to falling or even the prospect of sustaining a fall may be as crippling as actually experiencing a fall (Jorstad, Hauer, Becker, \& Lamb, 2005). As lowered self-confidence is exhibited by the older adult in his/her ability to perform daily activities without falling, a withdrawal or reluctance to engage in activities occurs (Jorstad et al., 2005). In the short term, curtailment of activities or avoidance may protect against falls. This restriction in the long term may diminish the physical and mental health of the older person, and 
negatively affects quality of life, and increase risk for falls (Jorstad et al., 2005; Vellas, Wayne, Pomero, Baumgartner, \& Garry, 1997).

Investigators have examined the correlation between FOF and fear-related activity restriction. Mann, Birks, Hall, Torgerson, and Watt (2006) conducted a study targeting this association and suggested that the older adult's living arrangement (living alone or not) is associated with FOF and withdrawal from activity. Likewise, Fletcher and Hirdes (2004) found that being alone during the daytime hours was a significant predictor of both FOF and activity restriction. Delbaere et al. (2004) attempted to correlate the amount of fear-related avoidance of activities with physical frailty in the older adult. They found the associations were most pronounced for mobility activities, such as walking and reaching, and less pronounced for ADL and social activities. They also found that the higher the number of activities the older adults avoided, the more difficult it was for them to perform those specific activities. They theorized that avoidance or withdrawal from activities dramatically accelerated the process of physical frailty in the older adult population due the devastating consequences of physical inactivity (Delbaere et al., 2004; McAuley, Mihalko, \& Rosengren, 1997).

Fear of falling and avoidance of activity due to FOF are common in older adults, in both fallers and those without history of falls (Tinetti, Speechley \& Ginter, 1988). In a large study published in 2009, Boyd and Stevens reported that approximately 36.8 percent of community-living older adults report having FOF. Data was collected from a large telephone survey from 2001 - 2003 and a follow-up conducted in 2005 with 1700 respondents. After adjustment for age and gender, being moderately fearful of falling is 
associated with decreased satisfaction with life, increased frailty and depressed mood, and recent experience with falls (Boyd \& Stevens, 2009; Cumming et al., 2000). Being very fearful of falling was associated with all of the above plus decreased mobility and social activities (Boyd \& Stevens, 2009; Cumming et al., 2000). Withdrawal from social and leisure physical activities is associated with decreased quality of life, increased frailty, and recent experience with falls (Yardley \& Smith, 2002). The study by Yardley and Smith yielded results indicating that the most common beliefs concerning the negative consequences of falling - loss of functional independence and the social consequence of damage to identity - were independently associated with FOF. The researchers found that FOF can potentially initiate a variety of behavioral changes that can adversely impact future health. Such adverse effects include worsened health and loss of balance, poor mobility, lower activity, higher levels of psychological distress, and poor quality of life, all of which can lead to institutional care (Legters, 2002; Tenetti, 2003; Yardley et al., 2002).

Avoidance of specifically feared activities, while related to general frailty in the older adult, is also related to specific components of physical functioning capacity, including weak or lessening muscle strength in the knee, poor hand grip strength and stability reductions in balance performance tests (Delbaere et al., 2004; Guskiewicz \& Perrin, 1996; Holmes, Jenkins, Adams, \& Spaulding, 2010). FOF might negatively impact the cognition of the older adult by creating a spiral of preoccupation and also lead to further deteriorations in strength. 
What fears, concerns, or anxieties underlie the development of FOF in the older adult? Mann, Birks, Hall, Torgerson, \& Watt (2006) suggested that FOF and withdrawal from activity were more than generalized anxiety symptoms. Specific assessment measures and interventions designed to reduce FOF in the older adult population do not take into account perceptions of anxiety associated with differences in personality. The aim of the study by Mann et al. was to make determinations about core personality traits as they may pertain to neuroticism as a predictor for the development of FOF in women over 70 years of age (2006). The Eysenck Personality Inventory was administered to make determinations about core predisposition to neuroticism. The researchers found that neuroticism was present in community-dwelling older women over 70 years old. Findings such as these represent a link with FOF, generalized neuroticism, and withdrawal from activity. The findings led to two interventions suggestions for FOF and withdrawal from physical activity. First, a link between neuroticism and FOF should be considered; making attempts to motivate people to change a behavior might prove futile if depression is evident. The older adult individual should resolve psychological disturbances before addressing FOF interventions. Second, a much more useful approach to individuals with neuroticism (and older adults in general) may be to emphasize the negative health outcomes of disengaging from physical and social activities, with less emphasis on fall consequences. This approach might be more successful with older adults who exhibit tendencies toward neuroticism (Mann et al., 2006). While a causal link between depression or neuroticism and FOF cannot be hypothesized in a crosssectional study, it is probable that FOF can and does lead to activity restriction and/or 
social isolation, which results in neuroticism and/or depression in the older adult (Gagnon, Flint, Naglie, \& Devins, 2005).

Interventions that Target Falls and FOF

Many intervention designs have falls and FOF as central components throughout the last decade or more. Programs that focus on helping the older adult understand some of the mechanisms behind fall risk have flourished. Educational programming to teach the older adult tips about removing trip hazards around the home or apartment has been designed both to reduce fall risk and lower FOF in order to keep older adults safe and independent in their homes. These programs have offered a wide variety of modalities, including those that offer only education to those that offer Tai-Chi and balance-specific exercises. While many have had limited success in group settings, those programs that are home-based most often have the highest adherence rates. Additionally, those that are limited in duration tend to be more preferred by the older adult population.

In a large meta-analytic review, McPhate, Simek \& Haines (2013) reviewed home-based exercise intervention programs that included balance exercises and walking. Those programs that had semi- to regular visits from an exercise instructor had the best adherence outcomes. Participants in home-based exercise programming for older adults who are at risk for falls and/or have reported fear of falling were only about 21 percent fully adherent to the programs. More specifically, the researchers initially reviewed 78 exercise and education intervention programs that were home-based; some were instructor-guided (McPhate et al., 2013). Most of the exercise programs that prescribed flexibility exercises had a high attrition rate. The researchers speculated that older adults 
may feel that flexibility had little to do with falls and thereby failed to see a health benefit of these programs. In contrast, home-based exercise programs that required walking were most often continued by the participants. Although similar meta-analyses found that such programs actually impacted the rate of falls, these researchers found no improvements or participant-reported lower fall rate.

In an intervention that compared exercise instruction to fall education, researchers Brouwer, Walker, Rydahl, \& Culham (2003) found that both groups showed significant improvement in the participants' perceived FOF. The exercise intervention sessions were conducted in small groups (approximately 3 participants per group) for an hour for eight weeks. The education-only group received information targeting and reducing risk factors for falls. More specifically, both programs reduced FOF but perceived physical health and activity improvements were realized only in the exercise-only group. In a program follow-up, benefits of both interventions were generally sustained. Neither group had measureable muscle strength improvements; neither group had increases in balance confidence (Brouwer et al., 2003).

Zijlstra et al. (2007) reviewed 19 studies targeting FOF and reduction in falls in the older population. The authors noted that more studies targeting specific FOF outcome measures should be performed. In addition, the meta-analytical review yielded home-based interventions to be superior unless the older adults were participating in community-based tai chi programming. These researchers found that the location of the training seemed to be as important as the mode of intervention. Situations that helped to reduce anxiety during the training were shown to be more effective in both outcome 
measures and attrition rate. The authors noted that FOF seemed to be a phenomenon associated with realistic assessment of one's ability to perform tasks without falling. They noted that future trials should be designed to include specific training interventions and reduced the multi-modal exercise format in order to ascertain causality.

Floor-Rise or Fall-Recovery Training

A limited number of studies have targeted floor-rise or fall-recovery in older adults. Although many researchers focusing on falls in the elderly, FOF, and activity disengagement have mentioned the strength and balance required to rise from a fallen position, few have focused on the specific strategies. Alexander, Ulbrich, Raheja, \& Channger (1997) first questioned the ability of older adults to rise from the floor. These researchers looked specifically at the body positions from the point of initial rise as well as whether or not the use of an assistive device, such as a chair, might impact the time and qualitative capacity of the participant to rise successfully from the floor. The researchers noted that healthy older adults took about twice as long to rise from a floor position than their younger counterparts, and congregate housing dwellers took two to three times longer than the healthy old. These researchers noted that healthier congregate housing dwellers rose more quickly than their frail counterparts and the most frail benefited greatly from using furniture as an assistive device.

In 2000, Ulbrich, Raheja, \& Alexander compared floor-rise techniques of two distinctly different groups. Their participants were healthy young college students (control group) and healthy older independent community-dwelling older adults (mean age 73 years) as well as congregate housing older adults (mean age 81 years). Using 
intermediate positions was critical to the time taken to rise from the floor. The congregate housing dwellers took the longest time to rise and used the most intermediate positionings of the body to actually come up from the floor. The young healthy college students used a floor-rise preferred strategy of "sit and crouch" while the healthy older adults modified their strategies to reflect a combination of tucking, crouching, kneeling, all-fours and a bear walk. A large number of the congregate housing dwellers (38 percent) were unable to rise from the floor without assistance. This group could manage preparatory rising body positions but failed to master any more challenging positions such as a crouch, kneeling, all-fours or a bear walk. The researchers suggested training older adults to manage intermediate body positioning as a method of fall-recovery or floor-rise training.

Hofmeyer, Alexander, Nyquist, Medell, \& Koreishi (2002) asked 17 volunteer participants to engage in a two-week floor-rise training and 18 volunteer participants to engage in a chair-based flexibility intervention (considered the control group) to determine the impact on rising from a fall in older adults. Both groups were timed on their ability to rise from the floor. In addition, both groups were videotaped to determine what starting positions were chosen before the training. The researchers noted whether the older adults started in a supine position or from all-fours during the baseline establishment phase of the study. The control group (chair-based flexibility training only) showed no improvements in the two-week period, but the floor-rise training group went from baseline mean 6.6 to intervention mean of 7.3, using an analysis of covariance (ANCOVA) (Hofmeyer et al., 2002). The researchers projected that such training 
methodologies might prove useful in training older adults to rise from the floor and of particular value when working with those at highest risk for falls. FOF Screening Tools

A number of screening tools have been developed to assess and/or measure FOF. Each uses different constructs and is based on different definitions of FOF assertions (Jung, 2008). For example, “fearful anticipation of a fall” (Silverton \& Tideiksaar, 1989, p. 145) might consist of a single-item question, such as “Are you afraid of falling?” with a “yes/no” or “fear/no fear” response design (Cameron, Stafford, Cumming, Birks, Kurrle, Lockwood, et al., 2000; Evitt \& Quiggley, 2004; Friedman, et al., 2002). The loss of confidence in balance (Falls Efficacy Scale, Tinetti et al., 1990), the ActivitiesSpecific Balance Confidence Scale (ABC, Powell \& Myers, 1995), and the Geriatric Fear of Falling Measure (Huang, 2006) all address FOF in their screening methods. While they have proven very useful in practice, these tools do not address activity restriction due to FOF. The Survey of Activities and Fear of Falling in the Elderly (SAFFE, Lachman et al., 1998), and the Modified SAFFE (mSAFFE, Yardley \& Smith, 2002) target self-imposed activity limitations that are a direct result of either a history of falling or FOF.

The SAFFE focuses on activity restriction, which is the most undesirable consequence of FOF. Since FOF leads to an increasingly sedentary lifestyle of physical and social activity restriction, the SAFFE targets this manifestation by questioning engagement in 11 activities with three response options: never avoid, sometimes avoid, and always avoid. The scoring is $0-3$, respectively. The possible SAFFE score range is 
0-33/11 and the higher score denotes a greater measure of activity restriction or complete withdrawal.

The psychometric properties of the SAFFE were validated through an itemreduction application that began with 22 items associated with those situations that caused the most fear for older adults in the original study. Although there are only 11 activities in the SAFFE, Lachman's validation process included a fear score for “activities performed, as well as those not performed" to designate the 22 individual items (Lachman et al., 1998, p. 46). In order to ensure that the screening tool maintained its internal consistency, the researchers used fear as the dependent variable, while using a forward regression procedure to apply each of the 22 items until more than 95 percent of the total "fear-score” was accounted for on the SAFFE (Lachman, et al., 1998, p. 46). The highest fear item was "going out when it is slippery," followed closely by "taking a tub bath.” Concerning specific activity restriction as reported by the respondents, half of them reported that they clean their home, walk specifically for exercise, go outside when it is slippery, walk several blocks outside, and go to see a movie or a live show less than they did five years ago (Lachman et al., 1998). The researchers reduced the 22-item original screening tool to 7, using this methodology, but achieved only reliability of .89, so they determined to add 4 additional items to attain a coefficient alpha of .91. As for the fear-scale aspect of the SAFFE, Lachman and colleagues looked specifically in FOF as it related to activity restriction. Those respondents who had higher fear-scores were engaged in fewer activities and were likely to have reduced all of those activities within the last 5 years as relative to the study. Using variables identified in previous research, 
Lachman et al. (1998) were able to examine variations in fear to obtain empirical validity for the SAFFE. For example, women and the very old (regardless of gender) were more likely to have higher fear of falling, as were those that had experienced a previous fall. Additionally, those people who used a walking aid or had more medical conditions had more FOF. The SAFFE has now been modified so that only 11 activities have been included.

In order to establish construct validity for the SAFFE, the researchers examined the relationship of FOF and quality of life. Using the SAFFE, the FES and a tool called the "Afraid item” which merely asked “Are you afraid of falling?” as a scoring method, the correlations indicated that more fear of falling is associated with poorer quality of life. These three screening protocols exhibited similar correlation magnitude. Construct validity was determined by questioning which targeted health and social indicators, physical functioning capacities, general health condition, chronic pain index, vitality, social support and the reliance on others for help, and one's general active and/or inactive modes of leisure. Using any of these three tools, all of the above-mentioned variables play a role in the scoring. The SAFFE has the ability to target a broader range of activities that might be affected by FOF and activity restriction, and it is useful in examining to what extent people engage in activities, although they might report some FOF. In current literature, researchers note that fear of falling is shown to be related to lower quality of life, even when controlling for related accompanying factors (Lachman et al., 1998; Boltz et al., 2013; Delbare et al., 2004; Rubenstein, 2006; Tinetti, 2003; Tinetti et al., 1988; Vellas et al., 1987). One advantage of this measure over existing 
measures is the possibility for differentiating fear of falling that leads to activity restriction from fear of falling that accompanies activity. Administration of the SAFFE tool may take longer than other screenings, but discerns succinctly exactly which activities are not performed due to FOF.

\section{Literature Summary}

Theoretical foundations for this study have been described in the literature review. One aspect of the research on FOF is that it has taken on a multifaceted approach. FOF has emerged as the result of older adults becoming supersensitive to changes in physical capacity and functioning, fear of losing independence and the belief that by withdrawal from activities offers more protection from falling.

As population trends continue, older adults are living longer as well as living longer in relatively independent settings. Such trends lead to observable patterns of disengagement by the older adult once FOF becomes pervasive. In a 2009 study by Boyd and Stevens, approximately 36.8 percent of the population over 65 years old reported a fear of falling. Although this FOF might not be extreme, it could easily become overpowering, causing disengagement from physical activities and spiraling downward until there is a huge impact on the person's quality of life.

While multimodal exercise interventions that target falls and FOF have shown some positive results, targeting the most successful specific intervention has proved elusive. Fall-recovery or floor-rise tactics have been suggested in many studies, but no interventions have used this type of training to target FOF changes. 
Although many tools target FOF, only the SAFFE addresses the actual level of activity restriction due to such fear (Lachman et al., 1998). The significance of fallrecovery training in exercise intervention programs has been mentioned in several studies as the one component in fall education that researchers had yet to propose. Such fallrecovery training would teach the older adult how to rise from a fallen position. Such training has the potential both to re-instill a sense of efficacy for the older adult and to serve as an initiative to stay physically active in the event of a fall. Instead of disengaging from physical activity, becoming or staying active is critical to maintaining strength and balance (Dias et al., 2011). 


\section{CHAPTER III}

\section{METHODS}

The purpose of this study was to determine if a fall-recovery (floor-rise) training protocol changed or lowered FOF scores. The SAFFE was used to measure this change (Lachman et al., 1998). A fall-education protocol was introduced to all participants in this study. The SAFFE survey tool measured baseline FOF scores, post-fall education scores as well as post-fall recovery (floor-rise) training scores.

\section{Participants}

Participants in this study were older adults residing in a continuum-of-care residential community. A total of 63 men and women were recruited from Friends Homes at Guilford and Friends Homes West in Greensboro, NC. The participants ranged in age from 73 to 101 years old.

More specifically, those residents who may have a fear of falling and/or reduce their engagement in activities due to such fear were the target of the participant recruitment process. The weekly newsletters, which are distributed to all independent and/or apartment residents at both campuses, were the primary recruitment tools. Only independent apartment residents were recruited for this study. An informed consent form, approved by the Institutional Review Board of the University of North Carolina at Greensboro, was provided to each potential participant, who signed and returned the form at the beginning or end of the initial information session. 
Any resident with a health condition - whether neurological, orthopedic, or other physical or cognitive impairment that might make rising from the floor unsafe - was excluded from this study. A physician's release for physical activity was required for all participants prior to their participation in this investigation (See Appendix 1: Physician's Release for Activity).

Recruitment was completed through the weekly newsletters distributed at each facility (Appendix 3: Recruitment Flyer). In particular, residents who either felt unusually stressed about falling or reported fear of falling and/or activity restriction were especially targeted and encouraged to volunteer by way of the newsletters. The student researcher is the Wellness Center Director for these retirement facilities, but this recruitment focused on a segment of this population who reported fear of falling or disengagement from activities. These residents who came to the information sessions and ultimately become part of this study rarely participated in any organized fitness programming; however any other interested resident who was already participating in a fitness program or using fitness equipment was allowed into this study. It was hoped that focusing on the recruitment of the most fearful in this population would increase the likelihood of lowering FOF in this intervention.

Fear of Falling Instrumentation

The Survey of Activities and Fear of Falling in the Elderly (SAFFE, Lachman et al., 1998) was used to analyze FOF levels as well as disengagement from activities. The SAFFE is included Appendix A. The SAFFE contains 11 activities of daily living (ADLs) and instrumental activities of daily living (IADLs). ADLs are considered basic 
self-care tasks necessary for maintaining independence. They include feeding, toileting, selecting proper attire, grooming, maintaining continence, putting on clothes, bathing, walking and transfers even if the person is wheelchair-bound. IADLs are typically more cognitively and physically complex or challenging. These include managing finances, arranging for transportation (which could include driving or arranging for a driver), shopping, preparing meals, using the telephone or other communication devices, managing medications, and household and basic home maintenance. The SAFFE was chosen as the measure for this study because it is designed to assess fear of falling. This survey tool measures activity restriction and a decline in quality of life of the individual. Fear-of-falling measures that do not assess these important aspects of impact and effect were not considered for this study.

The SAFFE poses several questions for each activity assessed in the 11 ADLs and IADLs to determine current level of activity, FOF, and activity restriction with the following questions "Do you currently do it?" "If you do the activity, when you do it, how worried are you that you might fall?” "Compared to 5 years ago, would you say that you do the activity more, the same, or less?”

Results of three items on the SAFFE can be reported in qualitative form to determine the number of activities that are not engaged in due to reasons other than FOF and to determine the number of activities that not done because of reasons other than FOF. Those lines include these questions: "Do you not do the activity because you are not worried, a little worried, somewhat worried, or very worried that you might fall?" "If 
you do not do the activity because of worry, are there other reasons that you do not do it?" "If you are not worried, what are the reasons that you do not do it?"

There are eleven activity items in the SAFFE screening tool: go to the store, prepare simple meals, take a tub bath, get out of bed, take a walk for exercise, go out when slippery, visit a friend or a relative, reach for something over your head, go to a place with crowds, walk several blocks outside, and bend down to get something. Guidelines for scoring the SAFFE are listed here:

A. Activity Level Scoring: Scored as the number of activities done out of 11 . This item in the SAFFE establishes whether the person is completely inactive (score of 0) or very active across the eleven items (score of 11). This score was not expected to change in the short duration of this study.

B. Fear of Falling Score: (see page 46 in Lachman et al., 1998). The FOF fear score is computed as the average worry scores across the 11 activities (or across as many of the activities that are done). Although "very worried" is line item \#1, the SAFFE instructions for scoring requires a recode so that "very worried" is 3 points and "not worried at all” is 0 points. All the FOF scores are totaled and divided by 11 , to give an average FOF score. The range is 0 to 3 , with 0 meaning that the person not worried at all across all eleven activities and 3 meaning that the person is very worried about doing all of the eleven activities. This measure was hypothesized to change in this study.

F. Activity Restriction Scoring: Number of the eleven activities that are reported as being done less than as compared to five years ago. According to guidelines for the 
SAFFE scoring, the number of "less than you used to" responses as compared to 5 years ago is the only line item to be scored. The possible scoring is $0-11$, with 11 representing doing all of the aforementioned activities less than 5 years ago. Activity restriction was very important for this study but was not expected to change during the short duration of this study.

Lines $\mathrm{C}$ and $\mathrm{D}$ are for scoring the reasons for not doing an activity other than or in addition to FOF and are both optional scoring tools and is described in full detail below:

C. and D. Recording the reasons for not doing an activity is optional per SAFFE guidelines, but knowing specifics of activity restriction for this study helped to lend indepth qualitative analysis. This was particularly important with a small number of participants in the floor recovery/intervention group. In the guidelines of the SAFFE, line C should be recorded as "not at all worried" initially just to establish that there are other reasons why respondents do not engage in an activity. A respondent who reports being very worried, somewhat worried, or a little worried will answer line D, which seeks to find other reasons in addition to FOF that the respondent does not do the activity listed in line A of the survey (11 ADLs and IADLs).

The SAFFE is fairly simple to administer and was found to be best completed in an interview form for this population. Generally, completion of the SAFFE survey questionnaire takes approximately 15-20 minutes but may take up to one hour. Such methodology requires more time-intensive data collection. This requirement limited the number of participants for this study to 63 . 


\section{Sample Power}

Due to the comprehensive nature of administering the survey and the individualized components involved in fall education and fall recovery (floor-rise) teaching tactics, keeping the number of participants low was crucial for data collection, analysis, and general time constraints of this study. To determine the sample size necessary to discern and report valid results, a power sample test was performed using SPSS, version 21 (IBM. 2013; Sunnassee, 2013). Based upon the constructs and proposed design of this study, it was then determined that for this study no fewer than 60 participants were necessary to perform a repeated measures analysis of variance (RM ANOVA) (Sunnassee, 2013). This information was used to guide the participant solicitation process in the information sessions.

\section{Hawthorne-Effect in Practice-Based Research}

Results from many research studies have been biased by participants receiving personalized attention during the data collection process. The Hawthorne-Effect is a phenomenon in which participants respond differently or change their behavior dramatically as a result of being in a research study. This phenomenon is particularly prevalent in case studies that require follow-up data collection such as that represented in this research. Such skewing of responses for such a phenomenon has been estimated as high as 13 percent in meta-analyses of follow-up research looking specifically at the Hawthorne-Effect (Fernald et al., 2012).

The potential for Hawthorne-type effects was anticipated to occur after the intervention and during the final data collection. Because the principal investigator was 
not blind to group membership, there was the possibility that she might bias participant responses. Therefore, it was determined that the third and final data collection would be performed by an individual who did not know the study participants or their group membership. This experimenter underwent extensive training prior to completing the third survey data collection. A small pilot study was performed on 6 older adults, ages 79-87.

During initial practice, the student researcher administered the SAFFE survey to the projected final experimenter. After two administrations, the final experimenter was then asked to administer the survey to the student researcher. Training continued with the final experimenter shadowing the administration of the SAFFE tool to one of the pilot group. The training continued by an orchestrated administration of the SAFFE tool to the remainder of the pilot group. After the second administration of the SAFFE to each member of the small pilot group (non-participants in this study), it was determined that this experimenter was sufficiently and satisfactorily trained for the third and final data collection, post-fall recovery training. Changes made for the primary research, based on the pilot study, included performing small-group sessions for fall-recovery training, speaking very slowly but deliberately during data collection, and repeating the respondent's replies during the course of the SAFFE administration.

\section{Procedures}

After advertising in the respective newsletters for study volunteers, a date was set for the initial group information session. There were a total of four information sessions, two at Friends West and two at Friends Guilford, over a period of four weeks. During 
this initial sign-up phase of the study, respondents were given an informed consent/physician's release for activity. For data collection purposes, random selection for the placement into either the control or intervention groups was performed as the informed consents were returned. This randomization was done by leaving the informed consents in their respective envelopes in groups of 6 , and pulling out 3 for the control group and 3 for the experimental group upon receipt. During the process of randomization, it was discovered that an additional 3 respondents assigned to the control group had either moved to another level of care (assisted living or memory care) or had died. This procedure and accompanying circumstances placed 30 individuals in the control group and 33 individuals in the intervention group.

Interviews

All 63 participants were interviewed in the first face-to-face meeting after the initial interest sessions at each facility. While most of the participants were comfortable being asked the questions on the SAFFE while the data was entered into an individually saved format on the laptop, several participants asked to hold the SAFFE while answering the questions. Three participants asked to take the SAFFE to their individual apartments (only on first administration of the SAFFE) to fill them out by pencil and return to the student researcher. Interview times ranged from 10 minutes to approximately 90 minutes in length with a mean time of $37.5(\mathrm{SD}=12.7)$ minutes. The surveys (pre-test, post-education, and post-fall recovery training) were administered between February 2013 and June 2013. In addition to material assessed using the 11- 
item SAFFE, the interview included requesting disclosure of the age of the participant. The FOF measure and the survey tool constructs were explained to each participant.

All participants were administered the pre-test SAFFE survey tool to assess current activity levels, level of FOF, and activity restriction. If the participants currently did not do one or more of the eleven activities listed in the first line of the SAFFE, the survey guided the query to a second line of questioning to determine their level of "worry" about falling. Activity levels in the SAFFE are rated whether participants do or do not do the activity, so the scoring of the eleven possible activities was simply $0-11$. In the second aspect of questioning about specific “worry” attitudes toward the specific activity, “worry” scores are ranked 0-3 by realizing an "average” worry score. The total amount of FOF is divided by 11, the number of activities in the survey tool, which equates to the FOF score. As previously mentioned, there could be reasons other than FOF or there could be reasons in addition to FOF that the respondents do not participate in one of the eleven activities listed on the SAFFE.

All participants were asked to attend the group educational sessions and all received fall-proofing materials (Falls and the Older Adult - NIH Senior Health) from the National Institute on Aging (NIH, 2013). Additionally, participants were instructed on fall statistics, causes of falls, and tips for fall-proofing their apartment and living area as described in the aforementioned literature (NIH, 2013).

Participants in this study lived in studio, one- or two- bedroom apartments, or in the cottages maintained by the continuing care retirement community. After the initial SAFFE administration, each participant was contacted for a personal interview/small 
group session lasting 20 minutes to one hour in his/her apartment or in a general area to discuss fall-proofing as per the educational material. To allow participants ample time to read the educational material and implement any changes to their apartments, the visit or session was no sooner than 8-14 days after the educational session. At the beginning of the visit or small group session, each participant was administered the SAFFE survey tool for the second time. No reliable changes were expected in the percentage of persons engaging in an activity or those reporting activity restriction was expected over a short data collection period. This SAFFE administration was conducted post-education for all 63 participants in this study.

Visits to members of the control group involved checking for any modifications outlined in the education checklist and answering any questions they might have about fall safety and fall-proofing of the apartments. Topics listed in the educational material included suggestions for keeping a clear pathway in more frequently traveled areas of their apartment, use of walkers or canes within the apartment, choice of rugs or throws, concerns about bed skirts or items that drape to the floor, etc. No additional educational intervention was provided at the follow-up visit for either group.

During the individual/small-group sessions for the fall-recovery group, each participant was guided through a series of fall recovery strategies for rising from the floor. In this part of the training, participants were asked to lie down in a supine position on the floor or mat table. Variations of the appropriate floor-rise strategies needed for successful fall-recovery were given on an individual basis. Each participant was guided personally, giving consideration to knee or hip replacement(s) and any orthopedic pre- 
existing conditions that might preclude using the dominant limb to stabilize in the static phase of ascent. These individual/small-group sessions allowed the investigator to personalize tactics for each participant, based on specific circumstances and capabilities. A few participants felt unsure of being able to rise from the floor initially but later asked to attempt the rise. Several participants in the floor-rise group used a foam mat (to simulate pulling a pillow off their bed or a throw from their couch) to assist them in situations when both knees and hips might have been somewhat affected, although to varying degrees of infirmary.

Specifically, participants were:

1. Shown and then guided through moving down to the floor,

2. Taught how to move from supine to side-lying position,

3. Instructed to place dominant or preferred leg out from body,

4. Instructed on foot placement before rising to accommodate broader base of support,

5. Shown how to push off with hands to move torso up from the floor,

6. Reminded to raise their heads slowly to avoid quick movements (vertigo, etc.),

7. Taught to place hands on quadriceps and/or "companion" chair,

8. Instructed to come up to a slow but steady upright position (CDC, 2013; Hofmeyer et al., 2002). 
Each participant who was able to perform the floor-rise maneuver attempted the movement two to three times in the individual/small group session. Videos of two participants performing their third floor-rise is included with this manuscript.

Again, to make sure that all participants had adequate time to implement educational fall-proofing strategies or for the intervention group to feel comfortable about floor-rise tactics specific to the individual, the last SAFFE survey administration was no sooner than 8-14 days after the apartment/small-group session. This third data collection was completed by the trained experimenter to reduce the likelihood of any Hawthorne Effect skewing of results (Fernald, 2012). Results from the final (third) survey administration were analyzed to compare changes in FOF, from both the first pre-test results and the post-education results. The data for this research was collected over a period of 6 months. Analysis

Pre-test, intermediate, and post-test SAFFE scores for both groups were compared using repeated measures analysis of variance (RM ANOVA). The IBM SPSS version 21 was used to construct a generalized linear model of descriptive statistics. This application allowed the comparison of baseline data (SAFFE \#1) prior to any intervention; and comparison of secondary data (SAFFE \#2) which was post-education; and final survey data (SAFFE \#3). 


\section{CHAPTER IV}

\section{RESULTS}

Results of the fall-recovery intervention are described in this chapter. Descriptive Data

Average FOF scores for each participant were computed for the SAFFE by totaling the raw worry score for the 11 targeted activities and dividing that number by eleven (the number of activities in the SAFFE), yielding a score range between 0-3. Other measures included mean age of all participants, mean activity scores, mean FOF score, and mean activity restriction score, including standard deviation. Table 1 (below) represents 3 SAFFE administration results for both the control group and the experimental group. 
Table 1. Descriptions, FOF Scores per Activity for Control and Intervention Groups

Control Group n=30

Mean Age 86.9 (SD 1.33)

\begin{tabular}{|c|c|c|c|c|c|c|}
\hline Activity & $\begin{array}{l}\text { SAFFE } \\
\# 1\end{array}$ & $\begin{array}{l}\text { SAFFE } \\
\# 2\end{array}$ & $\begin{array}{l}\text { SAFFE } \\
\# 3\end{array}$ & $\begin{array}{l}\text { SAFFE } \\
\# 1\end{array}$ & $\begin{array}{l}\text { SAFFE } \\
\# 2\end{array}$ & $\begin{array}{l}\text { SAFFE } \\
\# 3\end{array}$ \\
\hline Store & $0.63(.78)$ & $0.87(.81)$ & $0.70(.76)$ & $0.24(1.03)$ & $0.27(.95)$ & $0.15(.50)$ \\
\hline Meals & $0.10(.96)$ & $0.10(.96)$ & $0.10(.96)$ & $0.15(1.53)$ & $0.18(1.73)$ & $0.06(0.0)$ \\
\hline Tub & $0.37(.98)$ & $0.37(.98)$ & $0.33(1.0)$ & $0.36(.76)$ & $0.36(.76)$ & $0.18(.45)$ \\
\hline Bed & $0.57(.52)$ & $0.63(.67)$ & $0.60(.67)$ & $0.61(.58)$ & $0.61(.58)$ & $0.42(.39)$ \\
\hline Walk & $0.47(.58)$ & $0.47(.58)$ & $0.47(.58)$ & $0.45(.81)$ & $0.45(.81)$ & $0.27(.35)$ \\
\hline $\begin{array}{l}\text { Slippery } \\
\text { Visit }\end{array}$ & $1.60(.77)$ & $1.60(.77)$ & $1.50(.79)$ & 1.61(.82) & 1.61(.82) & $1.45(.83)$ \\
\hline Relative & $0.43(.67)$ & $0.47(.65)$ & $0.40(.71)$ & $0.30(.71)$ & $0.30(.71)$ & $0.21(.55)$ \\
\hline Reach & $0.60(.65)$ & $0.63(.66)$ & $0.60(.67)$ & $0.36(.30)$ & $0.36(.30)$ & $0.30(.52)$ \\
\hline $\begin{array}{l}\text { Crowds } \\
\text { Walk }\end{array}$ & $0.53(.65)$ & $0.53(.65)$ & $0.50(.67)$ & $0.24(.82)$ & $0.27(.76)$ & $0.15(.58)$ \\
\hline $\begin{array}{l}\text { Outside } \\
\text { Bend }\end{array}$ & $0.50(.67)$ & $0.53(65)$ & $0.50(.67)$ & $0.55(.92)$ & $0.55(.92)$ & $0.36(.63)$ \\
\hline Down & $0.60(67)$ & $0.63(.79)$ & $0.60(.79)$ & $0.48(.84)$ & $0.48(.84)$ & $0.42(.88)$ \\
\hline
\end{tabular}

As indicated, for this study the SAFFE tool was administered three times to all participants. All participants completed the SAFFE prior to beginning the study.

Additionally, all participants were given the second SAFFE after the education treatment, which included printed material Falls and Older Adults (NIH, 2013). Participants in this study were given the SAFFE for a third time by a data collector who had been trained by the primary investigator to avoid the Hawthorne Effect in sampling. The third and final survey was done after the intervention group had completed their fall recovery/floor rise training and both groups had ample time to make any fall safety changes to their apartments as per the recommendations in the NIH (2013) fall education handouts. Results from the original (or baseline) SAFFE administration indicated that more than 83 
percent and 84 percent of the participants (control and experimental, respectively) engaged in going for a walk; 83 percent and 94 percent in reaching up over their heads; 93 percent and 94 percent in preparing meals; 83 percent and 100 percent bending down to pick up something; 93 percent and 94 percent going to the store; 90 percent and 97 percent going into crowds; 97 percent and 100 percent visiting friends or relatives; and 100 percent getting out of bed (both groups).

Higher FOF scores on the SAFFE survey tool equate to greater fear for that activity. All of the participants in this study had relatively low fear of falling, even at the initial SAFFE administration. The percentage (both groups combined) who reported that they take a tub bath was the lowest of any that do any activity (13 percent and 15 percent) followed very closely by those who go out when slippery outside (16 percent and 18 percent). The third least often engaged-in activity was walking outside (50 percent and 61 percent). As indicated in Table 1, most participants reported getting out of bed more frequently than they did 5 years ago.

Repeated Measures Analysis of Variance (RMANOVA) was used to compare the two groups across the three measurement periods. SPSS (IBM, 2013) was used to analyze this data and a descriptive comparison of means was also performed. The following Figure \#1 shows a means comparison of first, second, and third SAFFE administration scores for the control and experimental groups. 
Figure 1. Mean Values for 3 SAFFE FOF Results

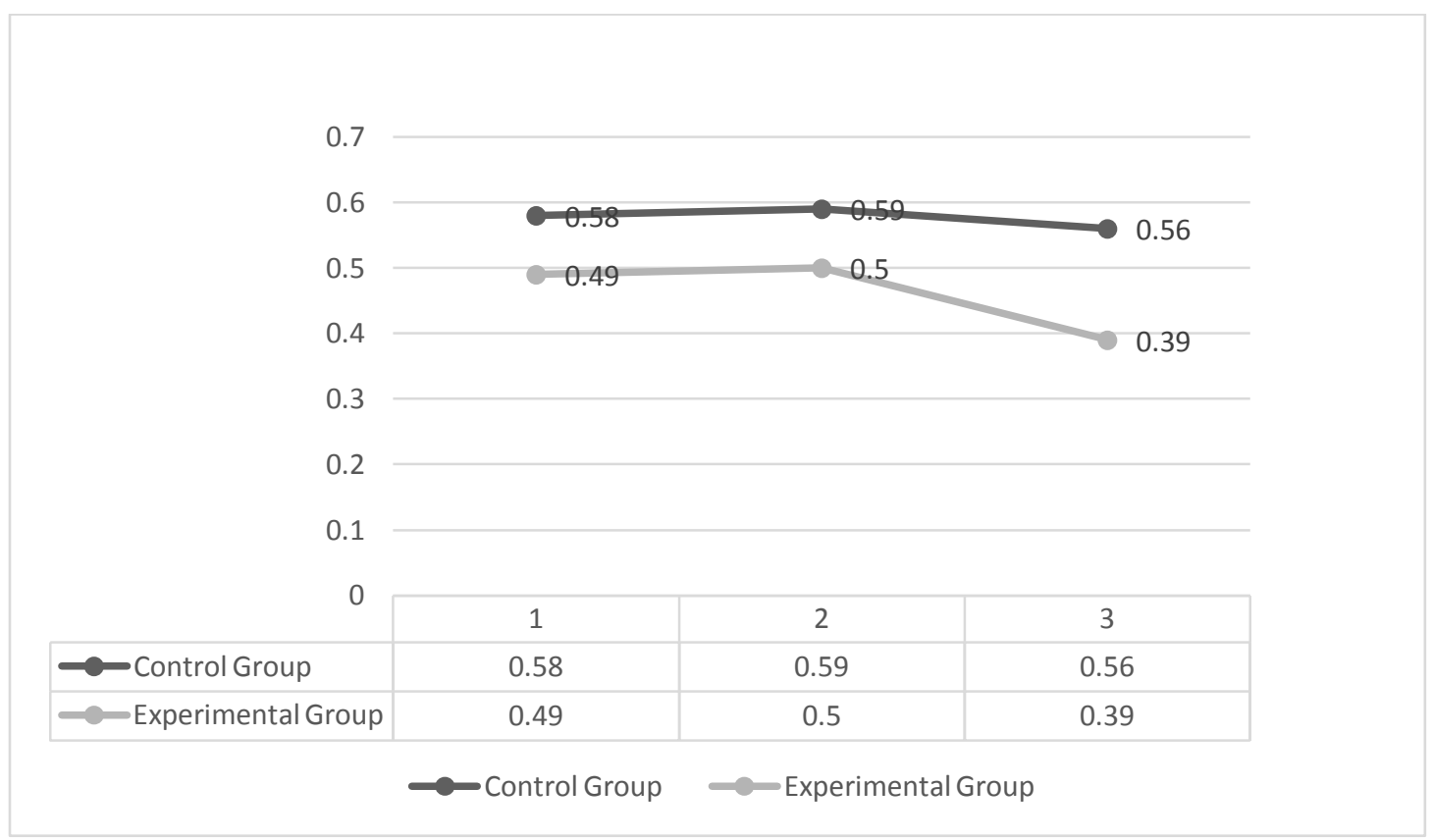

Sphericity is a mathematical assumption in descriptive statistics that refers to the homogeneity of the co-variances and variances in two population samples. In SPSS (version 21.0.1), Mauchly’s test of sphericity was not met in the repeated measures ANOVA. Using the more conservative Greenhouse-Geisser correction resulted in no significant findings in either group, time or interaction effects (p value=.36).

Although the FOF scores trended downward following the intervention, there was no significant decrease in FOF. There were no group or time main effects in this study that were significant ( $\mathrm{p}>.05)$. Additionally, there was no significant group $\mathrm{x}$ time interaction effects when analyzing using SPSS (IBM, 2013). This finding was probably due largely to the low level of fear participants demonstrated overall. Although noSIsignificant decreases in FOF were realized in this study, an alternative method for 
data analysis was sought that would detect a downward trend in FOF scores if those existed.

Because of the pilot nature of this study, examination of individual tasks with baseline FOF over 1.0 was undertaken. “Going out when slippery” (item \#6 on SAFFE) was the only item where this baseline occurred. A repeated measures ANOVA was performed on "Going out when slippery” for both groups for all three SAFFE administrations. Mauchly’s test of sphericity was not met. Using the more conservative Greenhouse-Geisser correction resulted in no significant findings in either group, time or interaction effects in for this line item (p value=.35).

FOF scores trended downward following the intervention for both groups but there was no significant decrease in FOF. There were no group or time main effects in this analysis. Additionally, there was no significant group $\mathrm{x}$ time interaction effects when analyzing using SPSS (IBM, 2013). Descriptive data for FOF on slippery surfaces is included in Figure 2. 
Figure 2. Mean Values for High Fear Activity - Slippery Surfaces (n=63)

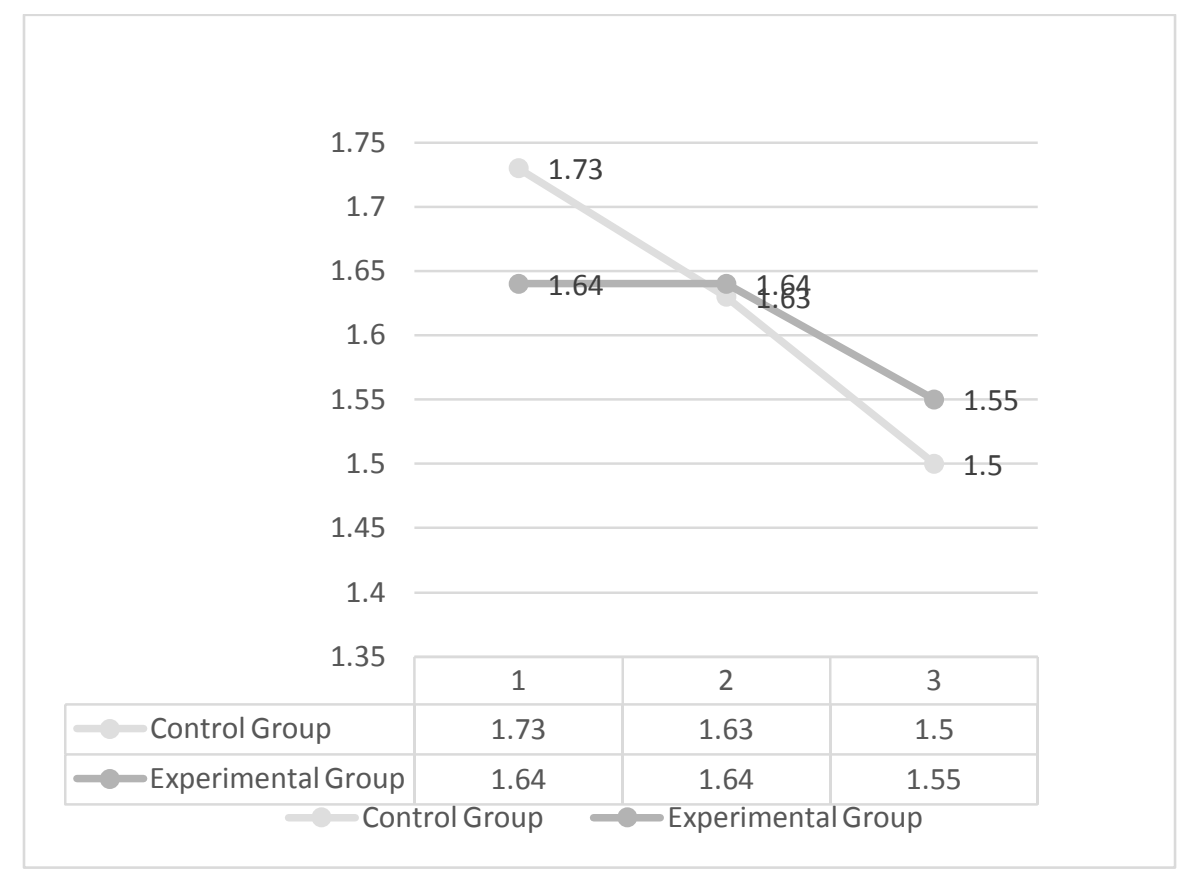

\section{Summary of Results}

Residents of the continuum-of-care community, from which participants in this study were recruited, had low levels of FOF at baseline measure. Because this style of community living may contribute to low levels of fear, participant recruitment and testing for FOF for older adults still living independently might be a consideration for future studies. Replicating the study in a group of individuals living in a more diverse collection of settings may produce different outcomes. 


\section{CHAPTER V}

\section{DISCUSSION}

The purpose of this study was to investigate FOF and the impact that both fallproofing education and fall-recovery/floor-rise training had on FOF. The two study hypotheses were (1) Both groups would have lower FOF scores compared to baseline after the fall education training using the SAFFE and (2) The experimental group would have lower FOF scores overall after the fall-recovery training compared with both baseline and post-education scoring using the SAFFE tool. Both hypotheses were rejected. A repeated measures ANOVA revealed no significant group, time, or interaction effects. The intervention group’s FOF scores trended downward following the training; however the difference was not statistically significant. The failure to find reliable differences was likely due in part to the relatively low overall FOF in both groups of participants.

The intervention group had a baseline score of .49, a post-education score of .50, and a final score of .39, which shows a modest decline or decrease in FOF. Scores for the control group remained stable across SAFFE \#1, \#2 and \#3 which is indicated in Table \#2 above. The participants in this study were not very fearful of falling at baseline (average FOF $<1.0$ ), indicating a possible floor-effect in FOF scoring for this population, using this instrument. Additional decreases in FOF were unlikely to be detected in this 
population using the SAFFE instrument. An intervention that had more floor-rise training times may have lowered FOF more over a longer period of intervention time. Additionally, data collection began in January and ended in July for this study. FOF scores as related to "going out when slippery” might have lowered due to seasonal climate changes in North Carolina.

\section{Alternative Sources or Causes of Activity Restriction}

Because many of the participants in this study had moved into this retirement community within the last five years, a drop in activities "as compared to five years ago" might be anticipated. Current living situations may also have played an important role. Factors may include giving up one’s car, relying on others for shopping and/or taking all of one's meals in the facility's dining rooms. Having retired, the participants might be less likely to venture out in slippery conditions; as reported, they may just wait for weather conditions to improve before going places in their cars or by public transportation unless unavoidable.

A retirement community such as those used in this study often has members of the population who are considerably more active and engaged in activities beyond the facility. At times, members of this group pick up groceries and do other shopping and/or banking errands for those with fewer capabilities.

Shubert, Altpeter and Busby-Whitehead (2011) noted that any research-based fall prevention intervention that begins as such a study needs thoughtful scrutiny before applying its results to the general population in communities at large. Assessing the core elements of this study are necessary, and perhaps future modifications and delivery of the 
education might be best performed with community partners or allies in the health support group. Translating a controlled data collection and floor-rise training to target a larger population of at-risk older adults in the community is necessary to prevent falls in this at-risk age group (Shubert et al., 2011).

Training in small groups or individually was relatively easy in this data collection; however, as Shubert et al. (2011) discussed, designing a community-based training protocol might post particular challenges. Slight modifications to this training protocol are needed before the training could be delivered to either large community settings or a health support team. Proper instruction and knowledge of participants' needs is very important to avoid injury and to guarantee successful fall recovery.

Results of this investigation indicate that any future examination of FOF and intervention modalities should use both quantitative and qualitative methods by examining both individual as well as group patterns of activity restriction as they relate to FOF. Scores in both groups changed very little, but anecdotal responses to the associated floor-rise training was very positive. The floor-rise group reported that they felt more empowered and independent after having learned specific techniques to rise from a fallen position. In addition, many of the participants in the intervention group advised other residents who were not in the study that they should learn how to rise from the floor. Most of the participants in the intervention group reported surprise at their own capabilities. These responses would only be detected in qualitative data collection and are not represented in the SAFFE scores for either group. Only a thorough observation of individual patterns of FOF increases might reveal any pattern of change as they 
specifically relate to both FOF and activity restriction. These issues as well as limitations to this study and future investigations will be discussed further in this chapter.

People move to continuing care retirement communities for specific reasons. Such reasons include lowering responsibilities of home upkeep, access to dining services, access to wellness or fitness venues, as well as housekeeping and medical services. Activity restriction as recorded in the SAFFE in this population, as mentioned previously, might not equate to a lowered quality of life. All of the participants in this study live in a continuing-care retirement community setting, so connectivity to global community activity venues might be expected to show change. Several of the participants reported that they gave up driving. These participants are less likely to go to the store as much, go to visit friends or relatives, and find themselves in crowds of people. Some of them reported riding the facility's busses to the grocery store, the bank, and local department stores rather than driving themselves. Many of the participants now find that one meal per day in the dining room has reduced their need to shop for groceries. Some of the participants mentioned taking all three meals in the dining room to avoid having to prepare meals in their apartments. Such changes would curtail the individual's need to go to the store, go into crowds, and generally to go out as much as someone who was still preparing meals in his/her apartment.

Uneven surfaces and poor or failing eyesight make walking several blocks outside a precarious activity. Most of the participants who do not walk outside or walk for exercise are doing activities indoors instead. Although it is uncertain how many participants in this study utilize a prescribed exercise program, many activities are 
available. For example, an extremely low-paced exercise class taught by one of the residents is offered at Friends Homes Guilford Monday-Friday mornings at 9:00 a.m., and this class boasts $20+$ people each day. Walking in the hallways, which are welllighted and on level surfaces, now replaces outside walking for many participants in this study who have decided to not expose themselves to what they perceive as unnecessary hazards.

Not taking a tub bath was not seen as a compromise by most of the participants. Comments ranged from "I have not taken a tub bath in years" to "tub baths are for babies”; and many similar reasons like these were repeated often. Approximately 12 participants who do not take tub baths reported that their upper body strength had declined to a point that they would not be able to get themselves up and out of the tub at the end of the bath. While FOF was sometimes a factor, it appeared to be only marginal in most of the activities “done less than 5 years ago” by this group of individuals.

\section{Research Implications and Future Directions}

The study represents a first step in a direction of research to allow older adults the opportunity to learn a floor-rise strategy as part of a successful intervention that may help decrease FOF. The design of an exercise program that strengthens muscle groups used when rising from the floor would be a best-practices approach for future exercise interventions. Exercises that help the older adult transition from chair to standing, toilet to standing, or in and out of an automobile are concerns expressed by this population.

The consequences of falls in the older adult population are great and can be devastating, so FOF is a common phenomenon (Boyd and Stevens, 2009). 
Unfortunately, activity restriction and ensuing muscle deconditioning are also becoming more common in an aging population. The older adults in this study, although varied in age, were in reasonably good health and lacked any major neurologic and orthopedic impairments. Teaching a new movement strategy, rising from the floor, as demonstrated by the difficulty experienced by some in the study, may be indicative of poor upper body strength or may be as simple as needing more practice time.

Characteristics of this population might be more homogeneous than those found in a community-based group of older adults. Residents of this retirement community are predominately Caucasian, retired from mostly semi-professional or professional careers and may therefore have had higher stable incomes and more access to the health care system. Researchers have noted that these factors tend to change older adults' attitudes toward falls (Rauch et al., 2009). The older adults in this study have generally traveled more and may be healthier and/or more-fit than older adults in a community setting.

Using this research design to construct a community-based program is very important. Doing so will require more in-depth analysis of the specific characteristics of this population, so as to make functional and physiological changes more applicable for the general population (Dias et al, 2011; Shubert et al., 2011). Additionally, making predictions about those changes might require employing a different and shorter questionnaire (Zarkou et al., 2011). FOF is not exclusive to just those participants who might have time to participate in a data survey that might take upwards of 90 minutes to complete; FOF surveys but should include older adults of any cognitive function and capability (Zarkou et al., 2011). 
FOF can be debilitating, especially for newly-released hospital patients (Boltz,et al., 2013). This debilitation may be especially the case for patients who are recovering from an orthopedic procedure which may have been necessitated by a fall. Methods for helping older adults transition from the hospital or rehabilitation center to their homes are critically important. The need for these methods will grow more important with the continued growth of this segment of the population. As the older adult seeks relief from orthopedic afflictions, it is critical that that person is capable of overcoming FOF in order to participate in post-surgical recuperative measures (Boltz et al., 2013). As FOF might be heightened in spending a few days in new surroundings, research must drive forward to find a way to abate FOF for a wide range of older adults in our population (Boltz et al., 2013).

Using the SAFFE, FOF results can be used to do targeted exercise or fall-recovery interventions. For example, in Dr. Lachman's (1998) original research, the level of fear results were then used to assign participants to balance testing and then training. Such assignment might target those individuals with high fear for personalized training either prior to fall-recovery training or as a fourth intervention protocol for testing.

Future research should include a more qualitative measure for FOF as well as a method for replicating the upper body and core strength necessary for rising from the floor. Although speculative from this research, an intervention program that included balance screening might be a tool that would assess the variability in the participants and provide an additional platform from which to collect additional tiers of data. 
The SAFFE tool took too long to administer. A shorter and simpler screening method is needed before undertaking a community-wide project. Assumptions could be made about the capabilities of older adults, and inclusion of floor-rise techniques for exercise programs might be an option. Such modifications would assist in building the bridge of individualized training to take it to a community-scaled basis (Shubert et al., 2011).

Overall, a more comprehensive collection of qualitative data in the form of a small case-study design might offer more detailed information as to what training protocol might help the older adult feel more confident, less fearful of falling and less likely to disengage from leisurely physical and social activities and thereby experience a continued life rich with quality. Finding a tool that helps to relieve anxiety and mental anguish associated with FOF might enrich the lives of older adults who experience it, and make visits to health care professionals, social events, or even to a family member’s home more enjoyable and less challenging (Boltz et al., 2013).

\section{Summary}

The SAFFE tool was used to measure fear of falling in a group of older adults living in a CCRC. Half of these elders participated in a rising-from-the-floor intervention hypothesized to decrease their overall fear. No statistically reliable decreases occurred following the intervention, due possibly to the already low FOF reported by these individuals. Future studies must identify and target elders with greater fear. Interventions with those more fearful elders may yield significant findings. 


\section{REFERENCES}

Alexander, N.B., Ulbrich, J., Raheja, A., \& Channer, D. (1997). Rising from the floor in older adults. Journal of the American Geriatrics Society, 45(5), 564-569.

Arfken, C. L., Lach, H. W., Birge, S. J., \& Miller, J. P. (1994). The prevalence and correlates of fear of falling in elderly persons living in the community. American Journal of Public Health, 84, 565-570.

Bandura, A. (1977). Self-efficacy: Toward a unifying theory of behavioral change. Psychological Review, 84, 191-215.

Bandura, A. (1982). Self-efficacy mechanism in human agency. American Psychologist, 37, 122-47.

Bandura, A. (1986). Social foundations of thought and action: A social cognitive theory. Englewood Cliffs, NJ: Prentice Hall.

Bandura, A. (1989). Social cognitive theory. In R. Vasta (Ed.), Annals of child development (Vol 6, pp.1-60). Greenwich, CT: JAI Press.

Bandura, A. (1991). Self-efficacy mechanism in physiological activation and healthpromoting behavior. In J. Madden (Ed.), Neurobiology of learning, emotion, and affect. New York: Raven Press.

Bandura, A. (2004). Health promotion by social cognitive means. Health Education and Behavior, 31,143-164. 
Barker, A. L., Nitz, J. C., Low Choy, N. L. \& Haines, T. (2009). Measuring fall risk and predicting who will fall: Clinimetric evaluation of four commonly used falls risk assessment tools for residential aged care. The Journals of Gerontology series A: Biological sciences and medical sciences, 64(8), 916-24.

Bhala, R.P., O’Donnell, J., \& Thoppil, E. (1982). Ptophobia: Phobic fear of falling and its clinical management. Physical Therapy, 62(2), 187-190.

Boltz, M., Resnick, B., Capezuti, E., \& Shuluk, J. (2013). Activity restriction vs. selfdirection: hospitalized older adults’ response to fear of falling. International Journal of Older People Nursing, 70, 1-9.

Boyd, R., \& Stevens, J.A. (2009). Falls and fear of falling: burden, beliefs, and behaviours. Age and Ageing, 38(4), 423-428.

Brouwer, B.J., Walker, C., Rydahl, SJ., \& Culham, E.G. (2003). Reducing fear of falling in seniors through education and activity programs: A randomized trial. Journal of the American Geriatrics Society, 51, 829-834.

Bruce, D.G., Devine, A., Prince, R.L. (2002). Recreational physical activity levels in healthy older women: the importance of fear of falling. Journal of the American Geriatrics Society, 50(1), 84-89.

Buchner, D.M., Cress, M.E., Wagner, E.H., de Lateur, B.J., Price, R., \& Abrass, I.B. (1993). The Seattle FICSIT/MoveIt study: the effect of exercise on gait and balance in older adults. Journal of the American Geriatrics Society, 41(3), 321325. 
Cameron, I.E., Stafford, B., Cumming, R.G., Birks, C., Kurrle, S.E., Lockwood, K., Quine, S., Finnegan, T., \& Salkeld, G. (2000). Hip protectors improve falls selfefficacy. Age and Ageing, 29(1), 57-62.

Centers for Disease Control and Prevention, National Center for Injury Prevention and Control. (2005). Web-based Injury Statistics Query and Reporting System (WISQARS). Available from URL: www.cdc.gov/ncipc/wisqars

Centers for Disease Control and Prevention. (2008). Self-reported falls and fall-related injuries among persons aged $\geq 65$ years --- United States, 2006. Morbitiy and Mortality Weekly Report, 57(09), 225-229.

Centers for Disease Control and Prevention: Division of Unintentional Injury Prevention National Center for Injury Prevention and Control. (2010). A CDC Compendium of Effective Fall Interventions: What Works for Community-Dwelling Older Adults: Exercise-based Interventions: Home Modification Interventions Multifaceted Interventions $2^{\text {nd }}$ edition (Authored by Stevens, J.A.) Retrieved on July 1, 2012 from http://www.cdc.gov/HomeandRecreationalSafety/pdf/CDC Falls Compendium l owres.pdf.

Centers for Disease Control and Prevention. (2013). Injury Prevention \& Control: Home and Recreational Safety. Falls Among Older Adults: An Overview. Available from URL: http://www.cdc.gov/HomeandRecreationalSafety/Falls/adultfalls.html 
Chang, J.T., Morton, S.C., Rubenstein, L.Z., Mojica, W.A., Maglione, M., Suttorp, M.J., et al. (2004). Interventions for the prevention of falls in older adults: systematic review and meta-analysis of randomised clinical trials. British Medical Journal, 328 (7441):680-687.

Chou, K., \& Chi, I. (2007). The temporal relationship between falls and fear-of-falling among Chinese older primary-care patients in Hong Kong. Aging and Society, 27(2):181-193.

Cumming, R. G. (1998). Epidemiology of medication-related falls and fractures in the elderly. Drugs Aging, 12(1), 43-53.

Cumming, R. G., Salkeld, G., Thomas, M., \& Szonyi, G. (2000). Prospective study of the impact of fear of falling on activities of daily living, SF-36 scores, and nursing home admission. Journals of Gerontology Series A-Biological Sciences and Medical Sciences, 55(5), M299-305.

Cummings, S. R., Rubin, S. M., \& Black, D. (1990). The future of hip fractures in the United States. Numbers, costs, and potential effects of postmenopausal estrogen. Clinical Orthopedics and Related Research, (252), 163-166.

Delbaere, K., Crombex, G., Vanderstraeten, G., Willems, T., \& Cambier, D. (2004). Fear-related avoidance of activities, falls and physical frailty. A prospective community-based cohort study. Age and Ageing, 33, 368-373.

Deshpande, N., Metter, E.J., Lauretani, F., Bandinelli, S., Guralnik, J., \& Ferrucci, L. (2008). Activity restriction induced by fear of falling and objective and 
subjective measures of physical function: a prospective cohort study. Journal of the American Geriatrics Society, 56, 615-620.

Dias, R.C., Freire, M.T.F, Santos, E.G.S., Vieira, R.A., Dias, J.M.D., \& Perracini, M.R. (2011). Brazilian Journal of Physical Therapy, 15(5), 406-413.

Diener, D., \& Mitchell, J. (2005). Impact of multicultural fall prevention program upon falls of older frail adults attending an adult day health center. Topics in Geriatric Rehabilitation, 21, 247-258.

Donald, I.P., Bulpitt CJ. (1999). The prognosis of falls in elderly people living at home. Age and Ageing, 28,121-5.

Evitt, C. P., \& Quigley, P. A. (2004). Fear of falling in older adults: A guide to its prevalence, risk factors, and consequences. Rehabilitation Nursing, 29, 207-210.

Eysenck, H.J., \& Eysenck, S.B. (1975). Manual of the Eysenck Personality Questionnaire, London: Hodder and Stroughton.

Faulkner, K.A., Cauley, J.A., Studenski, S.A., Landsittel, D.P., Cummings, S.R., Ensrud, K.E., Donaldson, M.G., \& Nevitt, M.C. 2009. Lifestyle predicts falls independent of physical risk factors - Study of oseteoporotic fractures research group. Osteoporosis International, 12, 2025-2034.

Fernald, D.H., Coombs, L., DeAlleaume, L., West, D., \& Parnes, B. (2012). An assessment of the Hawthorne Effect in practice-based research. Journal of the American Board of Family Medicine, 25(1), 83-86. 
Fletcher, P.C., \& Hirdes, J.P. 2004. Restriction in activity associated with fear of falling among community-based seniors using home care services. Age and Ageing, 33, 273-279.

Fried, L.P., Bandeen-Roche, K., Chaves, P.H., \& Johnson, B.A. (2000). Preclinical mobility disability predicts incident mobility disability in older women. Journals of Gerontology Series A- Biological Sciences and Medical Sciences, 55(1), M43M52.

Friedman, S.M., Munoz, B., West, S.K., Rubin, G.S., \& Fried, L.P. (2002). Falls and fear of falling: Which comes first? A longitudinal prediction model suggests strategies for primary and secondary prevention. Journal of the American Geriatric Society, 50, 1335-2002.

Gagnon, N., Flint, A., Naglie, G., \& Devins, G.M. (2005). Affective correlates of fear of falling in elderly persons. American Journal of Geriatric Psychiatry, 13, 7-14.

Ganz, D.A., Bao, Y., Shekelle, P.G., Laurence, Z. \& Rubenstein, M.D. (2007). Will my patient fall? (The) Journal of the American Medical Association, 297, 77-86.

Gates. S., Fisher, J.D., Cooke, M.W., Carter, Y.H., \& Lamb, S.E. (2008). Multifactorial assessment and targeted intervention for preventing falls and injuries among older people in community and emergency care settings: systematic review and metaanalysis. British Medical Journal, 336(7636):130-3.

Gill, D.L., Williams, K., Williams, L., \& Hale, W.A.. (1998). Multidimensional correlates of falls in older women. International Journal of Aging and Human Development, 47:35-51. 
Gill, T.M., Williams, C.S., \& Tinetti, M.E. 2000. Environmental hazards and the risk of nonsyncopal falls in the homes of community-living older persons. Medical Care, 38(12), 1174-1183.

Gillespie, L.D., Gillespie, W.J., Robertson, M.C., Lamb, S.E., Cumming, R.G., \& Rowe, B.H. (2003). Interventions for preventing falls in elderly people. Cochrane Database System Review, 4, CD000340.

Grisso, J.A., Kelsey, J.L., Strom, B.L., Chiu, G.Y., Maislin, G., O’Brien, L.A. (1991). The Northeast Hip Fracture Study. New England Journal of Medicine, 324(19), 1326-1331.

Guskiewicz, K.M., Perrin, D.H. (1996). Research and clinical applications of assessing balance. Journal of Sport Rehabilitation, 5, 45-63.

Hausdorff, J.M., Rios, D.A., \& Edleber, H.K. (2002). Gait variability and fall risk in community-living older adults: a 1-year prospective study. Archives of Physical Medicine and Rehabilitation, 82(8), 1050-1056.

He, W., Sengupta, M., Velkoff, V.A., \& DeBarros, K.A., U.S. Census Bureau (2005). Current Population Reports, P23-209, 65+ in the United States: 2005, U.S. Government Printing Office, Washington, DC.

Hofmeyer, M.R., Alexander, N.B., Nyquist, L.V., Medell, J.L., \& Koreishi, A. (2002). Floor-rise strategy training in older adults. Journal of the American Geriatrics Society, 50(10), 1702-1706.

Holmes, J.D., Jenkins, M.E., Johnson, A.M., Adams, S.G., \& Spaulding, S. J. (2010). Dualtask interference: the effects of verbal cognitive tasks on upright postural stability in Parkinson's Disease. Parkinson's Disease, vol. 2010, Article ID 696492, 5 pages. 
Howell, D. C. (2013) Statistical Methods for Psychology, 8th ed.. Belmont, CA: Cengage Wadsworth

Howland, J., Lachman, M.E., Peterson, E.W., Cote, J., Kasten, L., \& Jette, A. (1998). Covariates of fear of falling and associated activity curtailment. Gerontologist, 38, 549-55.

Howland, J., Peterson, W.W., \& Lachman, M.E. (2001). Falls among elderly persons. In S.E. Levkoff, Y.K. Chee, \& S. Noguchi (Eds.) Aging in good health: Multidisciplinary perspectives (pp. 221-245). New York: Springer.

Huang, T-T. (2005). Managing fear of falling: Taiwanese elders’ perspective. Internal Journal of Nursing Studies, 42, 745-750.

International Business Machines (IBM). 2013. SPSS ver. 21.August 2013

Jager, T.E., Weiss, H.B., Coben, J.H., \& Pepe, P.E. (2000). Traumatic brain injuries evaluated in U.S. emergency departments, 1992-1994. Academic Emergency Medicine, 7, 134-40.

Jorstad, E.D., Hauer, K., Becker, C., Lamb, S.E., (2005). Measuring the psychological outcomes of falling: A systematic review. Journal of the American Geriatrics Society, 53, 501-510.

Jung, D. (2008). Fear of falling in older adults: Comprehensive review. Asian Nursing Research, 2(4), 214-222.

Kannus, P., Sievanen, H., Palvanen, M., Jarinen, T. \& Parkkari, J. (2005). Prevention of falls and consequent injuries in elderly people. Lancet, 366(9500): 1885-93. 
Kogan, J.N., \& Edelstein, B.A. (2004). Modification and psychometric examination of a self-report measure of fear in older adults. Journal of Anxiety Disorders, 18(3), 397-409.

Kosorok, M.R., Omenn, G.S., Diehr, P., Koepsell, T.D., \& Patrick, D.L. (1992). Restricted activity days among older adults. American Journal of Public Health, 82(9), 1263-1267.

Kressig, R.W., Wolf, S.T., Sattin, R.W., O’Grady, M., Greenspan, A., Curns, A., \& Kutner, M. (2001). Associations of demographic, functional, and behavioral characteristics with activity-related fear of falling among older adults transition to frailty. Journal of American Gerontology Society, 49, 1456-1462.

Lach, H.W. (2003). Fear of falling: An emerging public health problem. Generations, 26(4), 33-38.

Lachman, M.E., Howland, J., Tennstedt, S., Jette, A., Assmann, S., \& Peterson, E.W. (1998). Fear of falling and activity restriction: The Survey of Activities and Fear of Falling in the Elderly. (SAFFE). Journal of Gerontology: Psychological Sciences, 53B, 43-50.

Lawrence, R.H., Tennstedt, S.L., Kasten, L.E., Shih, J., Howland, J., \& Jette, A.M. (1998). Intensity and correlates of fear of falling and hurting oneself in the next year: baseline findings from a Roybal Center fear of falling intervention. Journal of Aging Health, 10(3), 267-286.

Letgers, K. (2002). Fear of falling. Physical Therapy, 82, 264-272. 
Li, F., Fisher, K.J., Harmer, P., McAuley, E., \& Wilson, N.L. (2003). Fear of falling in elderly persons: Association with falls, functional ability, and quality of life. Journal of Geronotology: Psychological Sciences, 58B(5), 283-290.

Lusardi, M.M., \& Smith, E.V. (1997). Development of a scale to assess concern about falling and applications to treatment programs. Journal of Outcome Measurement, 2, 34-35.

McAuley, A., Mihalko, S.L., \& Rosengren, K. (1997). Self-efficacy and balance correlates of fear of falling in the elderly. Journal of Aging Physical Activity, 5, 329-340.

Magaziner, J., Hawkes, W., Hebel, J.R, Zimmerman, S.I., Fox, K.M., Dolan, M., Felsenthal, G., \& Kenzora, J. (2000). Recovery from hip fracture in eight areas of function. Journal of Gerontology-A Biological Science and Medical Sciences, 55, M498-M507.

Maki, B.E., Holliday, P.J., \& Topper, A.K. (1991). Fear of falling and postural performance in the elderly. Journal of Gerontology, 46, M123-M131.

Maki, B. E. (1997). Gait changes in older adults: predictors of falls or indicators of fear. Journal of the American Geriatriatrics Society, 45(3), 313-320.

Mann,R., Birks, Y., Hall, J., Torgerson, D., \& Watt, I. (2006). Exploring the relationship between fear of falling and neuroticism: a cross-sectional study in communitydwelling women over 70. Age and Ageing, 35, 143-147.

Marks, I., \& Bebbington, P. (1976). Space phobia: syndrome of agoraphobic variant? British Medical Journal, 2, 345-347. 
McPhate, L., Simek, E.M., Haines, T.P. 2013. Program-related factors are associated with adherence to group exercise interventions for the prevention of falls: a systematic review. Journal of Physiotherapy, 59(2), 81-92.

Metter, E.J., Talbot, L.A., Schrager, M., \& Conwit, R. (2002). Skeletal muscle strength as a predictor of all-cause mortality in healthy men. Journal of Gerontology, 57(10), B359-65.

Morley, J.E. (2007). Falls-where do we stand? Modern Medicine, 104(1), 63-67.

Murphy, J., \& Isaacs, B. (1982). The post-fall syndrome: A study of 36 elderly patients. Gerontology,28, 265-270.

Murphy, S.L., Williams, C.S., \& Gill, T.M. (2002). Characteristics associated with fear of falling and activity restriction among community-living older persons. Journal of the American Geriatrics Society, 50, 516-520.

Myers, A. M., Fletcher, P.C., Myers, A.H., \& Sherk, W. (1998). Discriminative and evaluative properties of the Activities-Specific Balance Confidence (ABC) Scale. Journal of Gerontology:Medical Sciences, 53A, M287-M294.

Myers, A. M., Powell, L. E., Maki, B. E., Holliday, P. J., Brawley, L. R., \& Sherk, W. (1996). Psychological indicators of balance confidence: Relationship to actual and perceived abilities. Journal of Gerontology: Medical Sciences, 51A, M37-M43.

National Blueprint. (2001). Increasing Physical Activity among Adults Age 50 \& Older. Princeton, NJ: The Robert Wood Johnson Foundation. 
National Institutes of Health. (2013). Falls and Older Adults. NIH Senior Health.

Retrieved on January 13, 2013 from

http://nihseniorhealth.gov/falls/homesafety/01.html.

National Safety Council. (2008). Falls leading cause of injury death for people 65 and older; medical costs of $\$ 19$ billion per year to more than double by 2020.

Retrieved on September 17, 2009 from http://www.nsc.org/news/nr050708.aspx.

Nelson, M.E., Rejeski, W.J., Blair, S.N., Duncan, P.W., Judge, J.O., King, A.C., Macera, C.A., \& Casteneda-Sceppa, C. (2007). Physical activity and public health in older adults. Recommendations from the American College of Sports Medicine and the American Heart Association. (2007). Circulation,116, 1094-1105.

Nevitt, M. C., \& Cummings, S. R. (1993). Type of fall and risk of hip and wrist fractures: the study of osteoporotic fractures. The Study of Osteoporotic Fractures Research Group. Journal of the American Geriatrics Society, 41(11), 1226-1234.

Nevitt, M. C., Cummings, S. R., \& Hudes, E. S. (1991). Risk factors for injurious falls: a prospective study. Journal of Gerontology, 46(5), M164-170.

Nevitt, M. C., Cummings, S. R., Kidd, S., \& Black, D. (1989). Risk factors for recurrent nonsyncopal falls. A prospective study. Journal of the American Medical Association, 261(18), 2663-2668.

Nevitt, M. C., de Rekeneire, N., Visser, M., Peila, R., Cauley, J. A., Tylavsky, F. A., et al. (2003). Is a fall just a fall: correlates of falling in healthy older persons. The health, aging and body composition study. Journal of the American Geriatrics Society, 51(6), 841-846. 
Norton, R., Campbell, A.J., Lee-Joe, T., Robinson, E., \& Butler, M. (1997).

Circumstances of falls resulting in hip fractures among older people. Journal of the American Geriatrics Society, 45(9), 1108-1112.

O’Loughlin, J.L., Robitaille, Y., Boivin, J.F., \& Suissa, S. (1993). Incidence of and risk factors for falls and injurious falls among the community-dwelling elderly. American Journal of Epidemiology, 137, 342-354.

Powell, L.E., \& Myers, A.M. (1995). The activities-specific balance confidence (ABC) scale. Journals of Gerontology Series A-biological Sciences and Medical Sciences, 50(1), 28-34.

Rai, G.S., Kiniorns, M., \& Wientjes, H. (1995). Falls Handicap Inventory (FHI): An instrument to measure handicaps associated with repeated falls. Journal of the American Geriatrics Society, 45, 723-724.

Rauch, K., Balascio, J., \& Gilbert, P. (2009). Excellence in action: developing and implementing a fall prevention program. Journal of Healthcare Quality, 31(1):36- 42.

Reelick, M.F., van Iersel, M.B., Kessels, R.P.C., olde Rikkert, M.G.M. (2009). The influence of fear of falling on gait and balance in older people. Age and Ageing, 38, 435-440.

Rubenstein, L.Z., \& Josephson, K.R. (2002). The epidemiology of falls and syncope. Clinics in Geriatric Medicine, 18(2), 141-158.

Rubenstein, L.Z. (2006). Falls in older people: epidemiology, risk factors and strategies for prevention. Age and Ageing, 35(S2), ii37-ii41. 
Salkeld, G., Cameron, I.D., Cumming, R.G., Easter, S., Seymour, J., Kurrie, S.E., \& Quine, S. (2000). Quality of life related to fear of falling and hip fracture in older women: A time trade off study. British Medical Journal, 320, 341-346.

Samelson, E.J., Zhang, Y., Kiel, D.P., Hannan, M.T., \& Felson, D.T. (2002). Effect of birth cohort on risk of hip fracture: Age-specific incidence rates in the Framingham Study. American Journal of Public Health, 92:858-62.

Scheffer, A.C., Schuurmans, M.J., van Dijk, N., van der Hooft, T., \& de Rooij, S.E. (2008). Fear of falling: measurement strategy, prevalence, risk factors and consequences among older persons. Age and Ageing, 37, 19-24.

Sherrington, C., Whitney, J.C., Lord, S.R., Herbert, R.D., Cumming, R.G., \& Close, J.C.T. (2008). Effective exercise for the prevention of falls: A systematic review and meta-analysis. Journal of the American Geriatrics Society, 56, 2234-2243.

Shubert, T.E., Altpeter, M., \& Busby-Whitehead, J. (2011). Using the RE-AIM framework to translate a research-based falls prevention intervention into a community-based program: Lessons learned. Journal of Safety Research, 42(6), 509-516.

Silverton, R., \& Tideiksaar, R. (1989). Psychological aspects of falls. In R. Tideiksaar (Ed.), Falling in older age: Its prevention and treatment, ( $2^{\text {nd }}$ ed.). New York: Springer.

Spano, A., Forstl, H. (1992). Falling and the fear of it. International Journal of Geriatric Psychiatry, 7, 149-151. 
Speechley, M., \& Tinnett, M. (1991). Fall and injuries in frail and vigorous community elderly persons. Journal of the American Geriatrics Society, 39(1), 46-52.

Steinweg, K.K. (1997). The changing approach to falls in the elderly. American Family Physician, 56(7), 1815-1823.

Sterling, D.A., O'Connor, J.A., Bonadies, J. (2001). Geriatric falls: injury severity is high and disproportionate to mechanism. Journal of Trauma-Injury, Infection and Critical Care,50(1), 116-119.

Stevens, J.A. (2005). Falls Free: Promoting a national falls prevention action plan. The National Council on Aging Research Review Papers.

Stevens, J.A. (2006). Fatalities and injuries from falls among older adults - United States, 1993-2003 and 2001-2005. Morbidity and Mortality Weekly Report, 55(45).

Stevens, J.A., \& Adekoya, N. (2001) Brain injury resulting from falls among elderly persons. Journal of the American Medical Association, 286(21),2665-2666.

Stevens, J.A., Corso, P.S., Finkelstein, E.A., \& Miller, T.R. (2006). The costs of fatal and non-fatal falls among older adults. Injury Prevention, 12(5), 290-295.

Stevens, J.A., \& Sogolow, E.D. (2005). Gender differences for non-fatal unintentional fall related injuries among older adults. Injury Prevention, 11(2), 115-119.

Sunnassee, D. (2011) Conditions Affecting the Accuracy of Classical Equating Methods for Small Samples Under the NEAT Design: A Simulation Study. UNCGreensboro Libraries. Retrieved on October $25^{\text {th }} 2013$, from http://libres.uncg.edu/ir/uncg/f/Sunnassee uncg 0154D 10782.pdf. 
Suzuki, M., Ohyama, N.,Yamada, K. \& Kanamori, M. (2002). The relationship between fear of falling,activities of daily living and quality of life among elderly individuals. Nursing and Health Sciences, 4,155-161.

Talley, K.M.C., Wyman, J.F., \& Gross, C.R. (2008). Psychometric properties of the Activities-Specific Balance Confidence Scale and the Survey of Activities and Fear of Falling in older women. Journal of the American Geriatrics Society, 56, 328-333.

Tennstedt, S., Howland, J., Lachman, M., Peterson, E., Kasten, L., \& Jette, A. (1998). A randomized, controlled trail of a group intervention to reduce fear of falling and associated activity restriction in older adults. The Journals of Gerontology, 53B(6), 384-392.

Tideiksaar, R. (2002). Falling in older people: Prevention and management ( $3^{\text {rd }}$ ed.). Springer: New York, NY.

Tinetti, M.E. (2003). Preventing falls in elderly persons. The New England Journal of Medicine, 348, 42-49.

Tinetti M.E., Speechley, M., Ginter, S.F. (1988). Risk factors for falls among elderly persons living in the community. The New England Journal of Medicine, 319, $1701-7$

Tinetti, M.E., Richman, D., \& Powell, L. (1990). Falls efficacy as a measure of fear of falling. Journal of Gerontology, 45, 239-243. 
Tinetti, M.E., Mendes de Leon, C.F., Doucette, J.T., \& Baker, D.I. (1994). Fear of falling and fall-related efficacy in relationship to functioning among communityliving elders. Journal of Gerontology, 49, M140-M147.

Tinetti, M.E. (2003). Preventing falls in elderly persons. New England Journal of Medicine, 348, 42-49.

Ulrich, J., Raheja, A., \& Alexander, N.B. (2000). Body positions used by healthy and frail older adults to rise from the floor. Journal of the American Geriatrics Society, 48(12), 1626-1632.

Underwood, M.R., Parsons, S., Eldridge, S.M.,Spencer, A.E., \& Feder, G.S. (2006). Asking older people about fear of falling did not have a negative effect. Journal of Clinical Epidemiology, 59, 629-634.

U.S. Census Bureau. International database. (2005). Midyear population, by age and sex. Retrieved on June 30, 2009 from http://www.census.gov/population/www/projections/natdet-D1A.html.

Vellas, B.J., Wayne, S.J., Pomero, L.J., Baumgartner, R.N.,\& Garry, P.J. (1997). Fear of falling and restriction of mobility in elderly fallers. Age and Ageing, 26, 189193.

Velozo, C.A., \& Peterson, C.W. (2001). Developing meaningful fear of falling measures for community dwelling elderly. American Journal of Physical Medicine \& Rehabilitation, 80(9), 662-673.

Verbrugge, L.M., \& Jette, A.M. (1994). The disablement process. Social Science and Medicine, 22(1), 95-106. 
Walker, J.E, Howland J. (1991). Falls and fear of falling among elderly persons living in the community: occupational therapy interventions. American Journal of Occupational Therapy, 45:119-122.

Yardley, L., Smith, H. (2002). A prospective study of the relationship between feared consequences of falling and avoidance of activity in community-living older people. Gerontologist, 42, 17-23.

Zarkou, A., Aggelousis, N., Michalopoulou, M., \& Tokmakidis, S. (2011). The impact of fear of falling, falls and gender on the quality of life in elderly people. Physiotherapy Issues, 7(1), 21-32.

Zijlstra, G.A., van Haastregt, J.C., van Rossum, E., van Eijk, J.T., Yardley, L., \& Kempen, G.I. (2007). Interventions to reduce fear of falling in community-living older people: a systematic review. Journal of the American Geriatrics Society, 55, 603-615. 
APPENDIX A

PHYSICIAN'S RELEASE

\section{Physician's Release for Participation in Physical Activity}

Dear Dr.

The following individual has indicated that you are his/her primary or attending physician. This individual has shown interest in participating in a study which requires moderate physical activity, which may include specific training on how to rise from the floor, formally termed "fall-recovery training." Please provide your recommendation(s) regarding such physical activity and any restrictions/limitations/comments/or concerns you have or might suggest for his/her participation in this specific program. Should you have any questions, please do not hesitate to contact me as indicated below. Thank you.

Participant/Resident:

\section{Resident Information Release:}

I, (Resident-participant's signature) request that on this day (date) that the physician listed above release this information to Teresa Cox (Wellness Center Director at Friends Homes, Inc. and Investigator for this study).

\section{Physician's Recommendation:}

Resident/Participant may engage in unrestricted physical activity Resident/Participant may engage in light to moderate activities only Resident/Participant should not engage in activity at this time Other: (Please specify below 
Please specify any restrictions or limitations you feel appropriate:

Physician (name)

Telephone (or fax)

Physician Signature

Contact Teresa Cox at TeresaCox@Friendshomes.org or 336-292-8187 Ext. 4228

Fax: (336) 294-0129 
APPENDIX B

INFORMED CONSENT

\section{UNIVERSITY OF NORTH CAROLINA AT GREENSBORO}

\section{Informed Consent}

Project Title: Fall-recovery intervention and its effects on fear of falling in older adults.

Project Director: Teresa B. Cox

Participant's Name:

\section{What is the study about?}

This is a research project, and the purpose is to determine if learning floor-rise or fall recovery training tactics has any impact on attitudes toward falling in the older adult.

\section{Why are you asking me?}

The reason that you have been selected as a participant in this research project is that you (a) are an independent apartment dweller at Friends Homes, and have volunteered to be part of this research project. You are being given a physician's release and if your primary care physician feels that you should not be part of this research project, this will exclude you from participation.

\section{What will you ask me to do if I agree to be in the study?}

You will be administered a survey when you sign in to be part of this study. Afterward, you will be given educational material concerning safety and fall-proofing your apartment and your surroundings. A visit to your apartment will be arranged so that you can take the survey a second time. This visit will occur no sooner than 5-7 days after your educational session. During this visit and via random selection, half of the participants will be given more extensive training and the other half will not have this additional portion of the research project. No sooner than 5-7 days later, after all have completed the additional portion of this project, all of you will be administered the survey again. The total time involved for all the data collection will be less than 3 hours, over a period of no more than 4 sporadic, non-continuous weeks. You may contact the researcher at 
any time to discuss any concerns that you might have about your participation in this research project.

Teresa B. Cox 336-508-8049

\section{Is there any audio/video recording?}

Yes, should your answers be such in the survey that moves to a section of the survey that gleans more qualitative conclusions, those answers (only) will be recorded to avoid errors. Any visual recordings done during fall-recovery training will require an informed photo consent.

\section{What are the dangers to me?}

The Institutional Review Board at the University of North Carolina at Greensboro has determined that participation in this study poses minimal risk to participants. As part of the extensive floor-rise training (should you be in the experimental group), you will be taught how to rise successfully from the floor.

If you have any concerns about your rights, how you are being treated or if you have questions, want more information or have suggestions, please contact Eric Allen in the Office of Research Compliance at UNCG toll-free at (855)-251-2351.

. Questions, concerns or complaints about this project or benefits or risks associated with being in this study can be answered by name of principal investigator Teresa Cox who may be contacted at (336 ) 508-8049 or tbcox@uncg.edu

\section{Are there any benefits to society as a result of me taking part in this research?} The results of this research project may help guide future fall-prevention training for older adults who experience fear of falling. The results of this research project may help mold safety and exercise guidelines for older adults who experience fear of falling.

\section{Are there any benefits to me for taking part in this research study?}

Participants in this research study will be given extensive fall-proofing guidelines that may help safeguard them from slips and trips in their apartment and in general leisurely outings. After data collection has occurred, all participants in this study will be taught floor-rise tactics.

\section{Will I get paid for being in the study? Will it cost me anything?}

There are no costs to you or payments made for participating in this study.

\section{How will you keep my information confidential?}

All data from this research study will be stored in a locked file cabinet. There will be no identifying data on the surveys. All information obtained in this study is strictly confidential unless disclosure is required by law.

\section{What if I want to leave the study?}

You have the right to refuse to participate or to withdraw at any time, without penalty. If you do withdraw, it will not affect you in any way. If you choose to withdraw, you may 
request that any of your data which has been collected be destroyed unless it is in a deidentifiable state.

\section{What about new information/changes in the study?}

If significant new information relating to the study becomes available which may relate to your willingness to continue to participate, this information will be provided to you.

\section{Voluntary Consent by Participant:}

By signing this consent form you are agreeing that you have read it, or it has been read to you, and you fully understand the contents of this document and are openly willing consent to take part in this study. All of your questions concerning this study have been answered. By signing this form, you are agreeing that you are 18 years of age or older and are agreeing to participate, or have the individual specified above as a participant participate, in this study described to you by Teresa B. Cox.

Signature: Date: 
APPENDIX C

RECRUITMENT IN NEWSLETTERS

Newsletter announcements - Both Facilities

For Friends West Newsletter:

Teresa Cox, a doctoral student at UNC-Greensboro in the department of Kinesiology is investigating fear of falling in the older adult population. More specifically, the purpose of her research is to use a survey that addresses fear of falling, as well as any activity restriction that result as an aspect of this fear. In addition, the research study will offer educational materials to all members of the study and floor-rise (fall recovery) tactics to half of the group. Independent apartment residents who would like to be part of this research study may contact Teresa Cox and pick up an informed consent/physician's release. This data collection will take place in activity room A of the Wellness Center at Friends Homes West.

At the end of the study, all remaining participants will be taught floor-rise (fall recovery) strategies if interested.

There will be an information session concerning this study on Thursday morning, January 17th in the large living room at 9:00 a.m. 


\section{For Friends Guilford Newsletter:}

Teresa Cox, a doctoral student at UNC-Greensboro in the department of Kinesiology is investigating fear of falling in the older adult population. More specifically, the purpose of her research is to use a survey that addresses fear of falling, as well as any activity restriction that result as an aspect of this fear. In addition, the research study will offer educational materials to all members of the study and floor-rise (fall recovery) tactics to half of the group. Independent apartment residents who would like to be part of this research study may contact Teresa Cox and pick up an informed consent/physician's release. This data collection will take place in the solarium at Friends Homes Guilford.

At the end of the study, all remaining participants will be taught floor-rise (fall recovery) strategies if interested.

There will be an information session concerning this study on Tuesday morning, January $21^{\text {st }}$ in the main living room at 9:00 a.m. 
APPENDIX D

SAFFE SURVEY TOOL

\section{SURVEY OF ACTIVITIES AND FEAR OF FALLING IN THE ELDERLY (SAFFE)}

Margie E. Lachman, Brandeis University and Jonathan Howland, Boston University

Research supported by NIA Roybal Center AG11669

Dear SAFFE User:

As you requested, I am sending a copy of the SAFFE. The scoring information is also included.

I grant you permission to use the SAFFE in your research. Please cite the following reference in your work:

Lachman, M. E., Howland, J., Tennstedt, S., Jette, A., Assman, S., \& Peterson, E. (1998). Fear of Falling and Activity Restriction: The Survey of Activities and Fear of Falling in the Elderly. Journal of Gerontology: Psychological Sciences, 53B, P43-P50.

I ask that you please send me preprints and/or reprints of any articles that you prepare which report results with the SAFFE. I am most interested to hear about the research you are doing. Good luck with your research project. Feel free to contact me if you have further questions.

Sincerely yours,

Margie E. Lachman, Ph.D.

Professor 
Scoring Information for Survey of Activities and Fear of Falling in the Elderly (SAFFE)

A. Activity Level: Scored as the number of activities they do out of 11. No and nonresponse are given a 0 and a yes is given a 1 . Count the number of 1's.

B. Fear of Falling: (see page 46 in Lachman et al., 1998) Recode scoring so that low scores mean low fear: $0=$ not at all, $3=$ very worried. Recode is $4=0,3=1,2=2,1=3$. The fear score is computed as the average worry scores across the 11 activities (or across as many of the activities that are done, i.e., if yes to A). Range is 0 to 3 .

F. Activity Restriction: Number of activities that are reported as doing less than used to. That is the number of "less than you used to" responses (response 3 ) to the question, Compared to 5 years ago, would you say that you.... (range is from 0 to 11 ).

Scoring the reasons for not doing an activity is optional (see page 48 in the 1998 article):

C. Count the "not at all worried" responses to determine the number of activities that are not done due to reasons other than fear of falling. D. Count the number of yes responses, to determine the number of activities that are not done because of other reasons in addition to fear of falling. 


\section{ACTIVITY QUESTIONNAIRE}

\begin{tabular}{|c|c|c|}
\hline $\begin{array}{l}\text { A. Do you } \\
\text { currently: }\end{array}$ & $\begin{array}{l}\text { 1. Go to the store? } \\
\begin{array}{l}\text { 1. No } \\
\text { Go to } \mathrm{C}\end{array} \\
\text { Go to B }\end{array}$ & $\begin{array}{l}\text { 2. Prepare simple meals? } \\
\begin{array}{ll}\text { 1. No } & \text { 2. Yes } \\
\text { Go to C } & \text { Go to B }\end{array}\end{array}$ \\
\hline $\begin{array}{l}\text { B. When you } \\
\text {...how worried are } \\
\text { you that you might } \\
\text { fall? }\end{array}$ & $\begin{array}{l}\text { 1. Very worried } \\
\text { 2. Somewhat worried } \\
\text { 3. A little worried, or } \\
\text { 4. Not at all worried } \\
\text { Go to F }\end{array}$ & $\begin{array}{l}\text { 1. Very worried } \\
\text { 2. Somewhat worried } \\
\text { 3. A little worried, or } \\
\text { 4. Not at all worried } \\
\text { Go to F }\end{array}$ \\
\hline $\begin{array}{l}\text { C. Do you not } \\
\text { (ACTIVITY) } \\
\text { because you are } \\
\text {...... that you might } \\
\text { fall? }\end{array}$ & $\begin{array}{l}\text { 1. Very worried } \\
\text { 2. Somewhat worried } \\
\text { 3. A little worried, or } \\
\text { 4. Not at all worried } \\
\text { Go to E }\end{array}$ & $\begin{array}{l}\text { 1. Very worried } \\
\text { 2. Somewhat worried } \\
\text { 3. A little worried, or } \\
\text { 4. Not at all worried } \\
\text { Go to E }\end{array}$ \\
\hline $\begin{array}{l}\text { D. Are there other } \\
\text { reasons that you do } \\
\text { not .... }\end{array}$ & $\begin{array}{l}\text { 1. NO } \\
\text { 2. YES_SPECIFY } \\
\text { GO TO F }\end{array}$ & $\begin{array}{l}\text { 1. NO } \\
\text { 2. YES_SPECIFY } \\
\overline{\text { GO TO F }}\end{array}$ \\
\hline $\begin{array}{l}\text { E. What are the } \\
\text { reasons that you do } \\
\text { not....... }\end{array}$ & SPECIFY: & SPECIFY: \\
\hline $\begin{array}{l}\text { F. Compared to } 5 \\
\text { years ago, would } \\
\text { you say that } \\
\text { you...... }\end{array}$ & $\begin{array}{l}\text { 1. More than you used to, } \\
\text { 2. About the same, or } \\
\text { 3. Less than you used to. }\end{array}$ & $\begin{array}{l}\text { 1. More than you used to, } \\
\text { 2. About the same, or } \\
\text { 3. Less than you used to. }\end{array}$ \\
\hline
\end{tabular}

\begin{tabular}{|c|c|c|}
\hline $\begin{array}{l}\text { A. Do you } \\
\text { currently: }\end{array}$ & $\begin{array}{l}\text { 3. Take a tub bath? } \\
\begin{array}{ll}\text { 1. No } & \text { 2. Yes } \\
\text { Go to } C & \text { Go to B }\end{array}\end{array}$ & $\begin{array}{l}\text { 4. Get out of bed? } \\
\begin{array}{ll}\text { 1. No } & \text { 2. Yes } \\
\text { Go to C } & \text { Go to B }\end{array}\end{array}$ \\
\hline $\begin{array}{l}\text { B. When you } \\
\text {...how worried are } \\
\text { you that you might } \\
\text { fall? }\end{array}$ & $\begin{array}{l}\text { 1. Very worried } \\
\text { 2. Somewhat worried } \\
\text { 3. A little worried, or } \\
\text { 4. Not at all worried } \\
\text { Go to F }\end{array}$ & $\begin{array}{l}\text { 1. Very worried } \\
\text { 2. Somewhat worried } \\
\text { 3. A little worried, or } \\
\text { 4. Not at all worried } \\
\text { Go to F }\end{array}$ \\
\hline $\begin{array}{l}\text { C. Do you not } \\
\text { (ACTIVITY) } \\
\text { because you are }\end{array}$ & $\begin{array}{l}\text { 1. Very worried } \\
\text { 2. Somewhat worried } \\
\text { 3. A little worried, or }\end{array}$ & $\begin{array}{l}\text { 1. Very worried } \\
\text { 2. Somewhat worried } \\
\text { 3. A little worried, or }\end{array}$ \\
\hline
\end{tabular}




\begin{tabular}{|c|c|c|}
\hline $\begin{array}{l}\text {...... that you might } \\
\text { fall? }\end{array}$ & $\begin{array}{l}\text { 4. Not at all worried } \\
\text { Go to } \mathrm{E}\end{array}$ & $\begin{array}{l}\text { 4. Not at all worried } \\
\text { Go to } \mathrm{E}\end{array}$ \\
\hline \multirow{3}{*}{$\begin{array}{l}\text { D. Are there other } \\
\text { reasons that you do } \\
\text { not .... }\end{array}$} & 1. NO & 1. NO \\
\hline & 2. YES_SPECIFY & 2. YES_SPECIFY \\
\hline & GO TO F & GO TO F \\
\hline $\begin{array}{l}\text { E. What are the } \\
\text { reasons that vou do }\end{array}$ & SPECIFY: & SPECIFY: \\
\hline not....... & & \\
\hline $\begin{array}{l}\text { F. Compared to } 5 \\
\text { years ago, would } \\
\text { you say that } \\
\text { you...... }\end{array}$ & $\begin{array}{l}\text { 1. More than you used to, } \\
\text { 2. About the same, or } \\
\text { 3. Less than you used to. }\end{array}$ & $\begin{array}{l}\text { 1. More than you used to, } \\
\text { 2. About the same, or } \\
\text { 3. Less than you used to. }\end{array}$ \\
\hline
\end{tabular}

\begin{tabular}{|c|c|c|}
\hline \multirow{3}{*}{$\begin{array}{l}\text { A. Do you } \\
\text { currently: }\end{array}$} & 5. Take a walk for exercise? & 6. Go out when slippery? \\
\hline & 1. No $\quad$ 2. Yes & 1. No $\quad$ 2. Yes \\
\hline & Go to B & Go to B \\
\hline $\begin{array}{l}\text { B. When you } \\
\text {...how worried are } \\
\text { you that you might } \\
\text { fall? }\end{array}$ & $\begin{array}{l}\text { 1. Very worried } \\
\text { 2. Somewhat worried } \\
\text { 3. A little worried, or } \\
\text { 4. Not at all worried } \\
\text { Go to F }\end{array}$ & $\begin{array}{l}\text { 1. Very worried } \\
\text { 2. Somewhat worried } \\
\text { 3. A little worried, or } \\
\text { 4. Not at all worried } \\
\text { Go to F }\end{array}$ \\
\hline $\begin{array}{l}\text { C. Do you not } \\
\text { (ACTIVITY) } \\
\text { because you are } \\
\text {..... that you might } \\
\text { fall? }\end{array}$ & $\begin{array}{l}\text { 1. Very worried } \\
\text { 2. Somewhat worried } \\
\text { 3. A little worried, or } \\
\text { 4. Not at all worried } \\
\text { Go to E }\end{array}$ & $\begin{array}{l}\text { 1. Very worried } \\
\text { 2. Somewhat worried } \\
\text { 3. A little worried, or } \\
\text { 4. Not at all worried } \\
\text { Go to E }\end{array}$ \\
\hline $\begin{array}{l}\text { D. Are there other } \\
\text { reasons that you do }\end{array}$ & $\begin{array}{l}\text { 1. NO___SPECIFY } \\
\text { 2. YES_S }\end{array}$ & $\begin{array}{l}\text { 1. NO } \\
\text { 2. YES_SPECIFY }\end{array}$ \\
\hline & GO TO F & GO TO F \\
\hline $\begin{array}{l}\text { E. What are the } \\
\text { reasons that you do } \\
\text { not....... }\end{array}$ & SPECIFY: & SPECIFY: \\
\hline $\begin{array}{l}\text { F. Compared to } 5 \\
\text { years ago, would } \\
\text { you say that } \\
\text { you...... }\end{array}$ & $\begin{array}{l}\text { 1. More than you used to, } \\
\text { 2. About the same, or } \\
\text { 3. Less than you used to. }\end{array}$ & $\begin{array}{l}\text { 1. More than you used to, } \\
\text { 2. About the same, or } \\
\text { 3. Less than you used to. }\end{array}$ \\
\hline
\end{tabular}

\begin{tabular}{|l|l|l|}
\hline $\begin{array}{l}\text { A. Do you } \\
\text { currently: }\end{array}$ & 7. Visit a friend or relative? & $\begin{array}{l}\text { 8. Reach for something } \\
\text { over your head? }\end{array}$ \\
\hline
\end{tabular}




\begin{tabular}{|c|c|c|}
\hline & $\begin{array}{ll}\text { 1. No } & \text { 2. Yes } \\
\text { Go to C } & \text { Go to B }\end{array}$ & $\begin{array}{ll}\text { 1. No } & \text { 2. Yes } \\
\text { Go to C } & \text { Go to B }\end{array}$ \\
\hline $\begin{array}{l}\text { B. When you } \\
\text {...how worried are } \\
\text { you that you might } \\
\text { fall? }\end{array}$ & $\begin{array}{l}\text { 1. Very worried } \\
\text { 2. Somewhat worried } \\
\text { 3. A little worried, or } \\
\text { 4. Not at all worried } \\
\text { Go to F }\end{array}$ & $\begin{array}{l}\text { 1. Very worried } \\
\text { 2. Somewhat worried } \\
\text { 3. A little worried, or } \\
\text { 4. Not at all worried } \\
\text { Go to F }\end{array}$ \\
\hline $\begin{array}{l}\text { C. Do you not } \\
\text { (ACTIVITY) } \\
\text { because you are } \\
\text {..... that you might } \\
\text { fall? }\end{array}$ & $\begin{array}{l}\text { 1. Very worried } \\
\text { 2. Somewhat worried } \\
\text { 3. A little worried, or } \\
\text { 4. Not at all worried } \\
\text { Go to E }\end{array}$ & $\begin{array}{l}\text { 1. Very worried } \\
\text { 2. Somewhat worried } \\
\text { 3. A little worried, or } \\
\text { 4. Not at all worried } \\
\text { Go to E }\end{array}$ \\
\hline $\begin{array}{l}\text { D. Are there other } \\
\text { reasons that you do } \\
\text { not .... }\end{array}$ & $\begin{array}{l}\text { 1. NO___SPECIFY } \\
\text { 2. YES_SP F F }\end{array}$ & $\begin{array}{l}\text { 1. NO } \\
\text { 2. YES_SPECIFY } \\
-\overline{G O} \text { TO F }\end{array}$ \\
\hline $\begin{array}{l}\text { E. What are the } \\
\text { reasons that you do } \\
\text { not....... }\end{array}$ & SPECIFY: & SPECIFY: \\
\hline $\begin{array}{l}\text { F. Compared to } 5 \\
\text { years ago, would } \\
\text { you say that } \\
\text { you...... }\end{array}$ & $\begin{array}{l}\text { 1. More than you used to, } \\
\text { 2. About the same, or } \\
\text { 3. Less than you used to. }\end{array}$ & $\begin{array}{l}\text { 1. More than you used to, } \\
\text { 2. About the same, or } \\
\text { 3. Less than you used to. }\end{array}$ \\
\hline
\end{tabular}

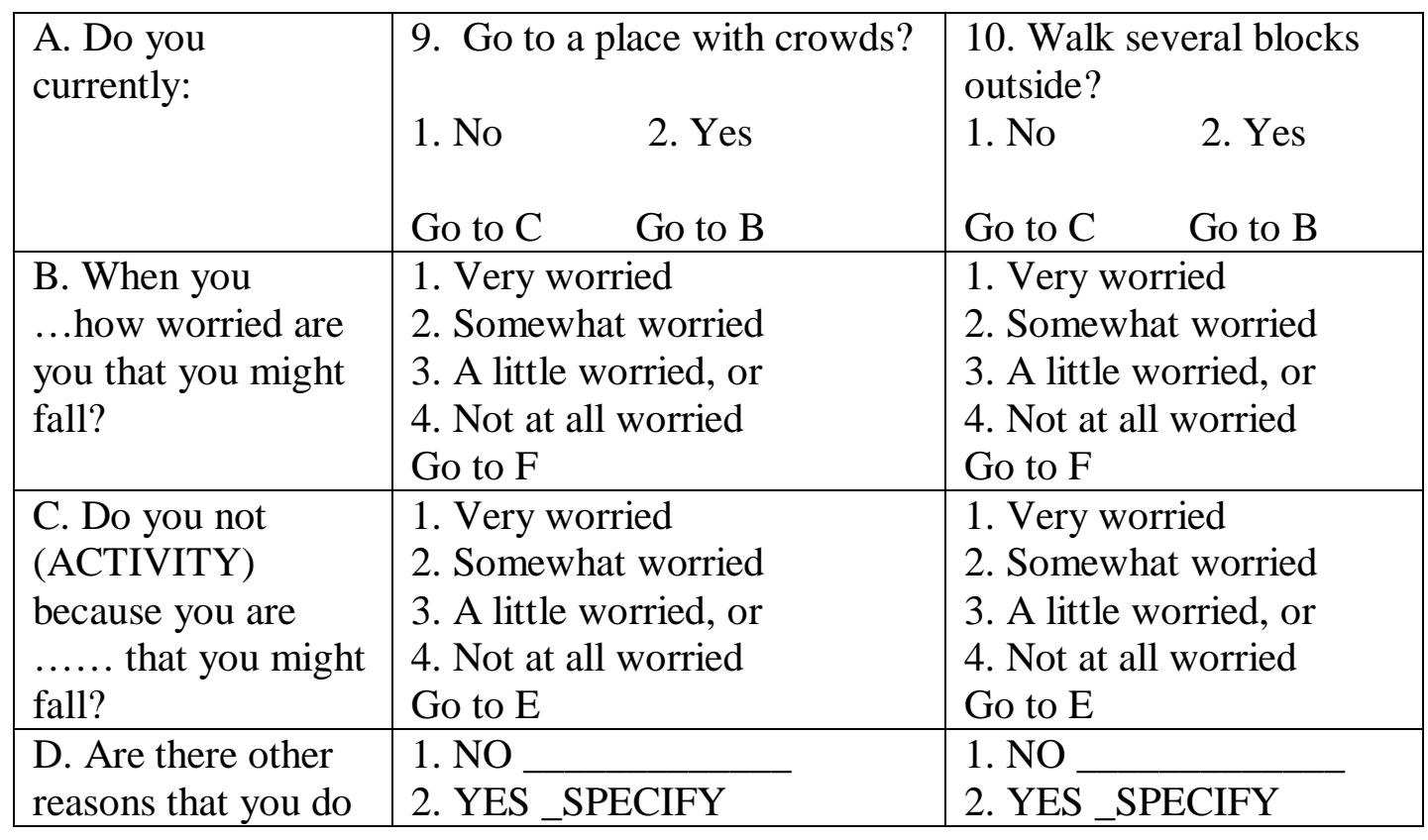




\begin{tabular}{|l|l|l|}
\hline not .... & GO TO F & \\
\hline $\begin{array}{l}\text { E. What are the } \\
\text { reasons that you do } \\
\text { not....... }\end{array}$ & SPECIFY: & SPECIFY: \\
\cline { 2 - 3 } $\begin{array}{l}\text { F. Compared to 5 } \\
\text { years ago, would } \\
\text { you say that } \\
\text { you...... }\end{array}$ & $\begin{array}{l}\text { 1. More than you used to, } \\
\text { 2. About the same, or } \\
\text { 3. Less than you used to. }\end{array}$ & $\begin{array}{l}\text { 1. More than you used to, } \\
\text { 2. About the same, or } \\
\text { 3. Less than you used to. }\end{array}$ \\
\hline
\end{tabular}

\begin{tabular}{|c|c|}
\hline $\begin{array}{l}\text { A. Do you } \\
\text { currently: }\end{array}$ & $\begin{array}{l}\text { 11. Bend down to get } \\
\text { something? } \\
\begin{array}{ll}\text { 1. No } & \text { 2. Yes } \\
\text { Go to C } & \text { Go to B B }\end{array}\end{array}$ \\
\hline $\begin{array}{l}\text { B. When you } \\
\text {...how worried are } \\
\text { you that you might } \\
\text { fall? }\end{array}$ & $\begin{array}{l}\text { 1. Very worried } \\
\text { 2. Somewhat worried } \\
\text { 3. A little worried, or } \\
\text { 4. Not at all worried } \\
\text { Go to F }\end{array}$ \\
\hline $\begin{array}{l}\text { C. Do you not } \\
\text { (ACTIVITY) } \\
\text { because you are } \\
\text {..... that you might } \\
\text { fall? }\end{array}$ & $\begin{array}{l}\text { 1. Very worried } \\
\text { 2. Somewhat worried } \\
\text { 3. A little worried, or } \\
\text { 4. Not at all worried } \\
\text { Go to E }\end{array}$ \\
\hline $\begin{array}{l}\text { D. Are there other } \\
\text { reasons that you do } \\
\text { not .... }\end{array}$ & $\begin{array}{l}\text { 1. NO___SPECIFY } \\
\text { 2. YES_GO TO F }\end{array}$ \\
\hline $\begin{array}{l}\text { E. What are the } \\
\text { reasons that you do } \\
\text { not....... }\end{array}$ & SPECIFY: \\
\hline $\begin{array}{l}\text { F. Compared to } 5 \\
\text { years ago, would } \\
\text { you say that } \\
\text { you...... }\end{array}$ & $\begin{array}{l}\text { 1. More than you used to, } \\
\text { 2. About the same, or } \\
\text { 3. Less than you used to. }\end{array}$ \\
\hline
\end{tabular}




\section{APPENDIX E}

\section{AUTHORIZATION FOR PHOTOS AND FILMING}

\section{Authorization for Use or Disclosure of Protected Health Information}

Name of Resident/Employee:

Date:

I hereby authorize the use and disclosure of my health information as indicated below. I understand that this release is voluntary and that I may revoke this authorization at any time except to the extent that action has been taken in reliance on this authorization. I also understand that if the individual or organization authorized to receive this information is not required to comply with current privacy regulations, my health information may be disclosed to others and no longer protected by current state and federal privacy regulations.

I hereby authorize the release of the information checked and/or listed below for the time period beginning on and ending on

[ ] Face Sheet [ ] MAR (Medication Administration Record)

[ ] Telephone Orders [ ] Therapy Notes

[ ] Complete health care record(s) [ ] Discharge Summary

[ ] History \& Physical Examination [ ] Progress Notes

[ ] Minimum Data Set [ ] Care Plans

[ ] Laboratory Reports [ ] Dental Records

[ ] Medical / Treatment Records [ ] Photographs, Video Tapes, Digital,

[ ] Pathology Reports or otherimages

[ ] X-Ray Reports [ ] Billing Statements

[ ] Transcribed Reports [ ] Emergency Care Records

[ ] Nurses' Notes [] Consultant Reports

[ ]

Other:

[ ]

Other:

[ ]

Other:

The information checked and/or listed above is to be released to: for the purpose of 
I understand that the individual, organization, or entity receiving my health information may receive financial or in-kind compensation in exchange for using or disclosing the information described above.

Unless otherwise revoked by me, I understand that this authorization will expire on or upon the completion of the use of the information for the purpose it was intended, whichever is earlier.

I understand that I may refuse to sign this authorization and that my refusal to sign will not affect my ability to obtain treatment or payment or my eligibility for benefits.

I understand that I may inspect and copy any information used or disclosed under this authorization. I understand that a fee may be charged for such copying services.

I hereby release the organization, its employees, officers, and health care professionals from any legal responsibility or liability for disclosure of the above information to the extent indicated and authorized herein.

I understand that I may revoke this request at anytime by providing the organization with my written notice of such revocation.

Date: Signature of

Resident:

Printed Name of Resident:

Date:

Signature of

Representative:

Printed Name of Representative:

Relationship to Resident:

Date:

Signature of

Witness:

Printed Name of Witness:

A copy of this record must be provided to the person making the request and a copy must be filed in the medical record. The original is to be returned to the HIPAA Privacy and Security Officer. 